\title{
XXVI,
}

\section{Beiträge zur Kenntniss des Faserverlaufes im Pes pedunculi sowie über die corticalen Beziehungen des Corpus geniculatum internum.}

\author{
Von \\ Dr. Theodor Zacher, \\ Dirigirendem Arztẻ der v. Ehrenwall'schen Anstalt für Ndrven- und Gemüthsiranke \\ (früher II. Arzt in Stephansfeld.)
}

\begin{abstract}
Im Anschlusse und gewissermassen als Ergänzung meiner früheren Untersuchungen ${ }^{*}$ ) über secundäre Degenerationen im Grosshirnschenkelfuss möchte ich heute nachfolgende Arbeit der Oeffentlichkeit übergeben. Sie enthält die Untersuchnngen von vier Fällen mehr oder weniger ausgedehnter Erweichungen im Gehirne, welche sämmtlich secundäre Degenerationen im Grosshirnschenkelfuss und zwar an verschiedenen Stellen desselben hervorgerufen hatten und die hierdurch Gelegenbeit geben, die in manchen Punkten noch dunklen und umstrittenen Fragen über die Lage und Dignität der einzelnen hier verlaufenden Faserbündel aufzuklären. Ausserdem aber bieten die Fälle auch noch dadurch ein Interesse, dass sich in allen neben sonstigen secundären Degenerationen degenerative Veränderungen im Corpus geniculatum internum vorfanden, welche gleichfalls im Anschlusse und in Folge Zerstörung bestimmter Hirnbezirke aufgetreten waren.
\end{abstract}

\section{Beobachtung.}

Bey, Heinrich, lediger Ackerknecht, 60 Jahre alt; aufgenommen am 2. April 1887, gestorben am 1. August 1888 .

*) Dieses Arehir Bd. XIX. Heft 3. 
Anamnestisch wurde bekannt, dass Patient früher sehr viel trank, im Spätherbste 1886 einen Schlaganfall erlitt und da er hierdurch arbeitsunfähig wurde, sich bettelnd herumtrieb und in Folge dessen mit der Polizei in Conflict kam. Da er im Gefängnisse durch sein Verhalten Verdacht auf Geistesstörung erregte, wurde er nach Stephansfeld gobracht, wo er bei seiner Aufnahme folgenden Status darbot.

Kleines, ziemlich gut genährtes Individuum, das keinen auffälligen Schädelbau darbietet. Pupillen sehr enge, aber gleich, zeigen deutlicbe Lichtreaction. Der rechte Mundwinkel steht tiefer, die Zunge weicht beim Vorstrecken etwas nach rechts ab. Kein Tremor derselben. Beim Gehen hebt Patient die Füsse kaum vom Boden und schleppt er dabei das rechte Bein etwas nach, doch ist im Uebrigen der Gang sicher. Er benulzt beide Arme. doch scheint es, als ob er den linken mit Vorliebe gebrauche; dabei sind alle Bewegungen der oberen Extremitäten etwas unbebolfen und plump. Störungen der Sensibilität sind nicht vorbanden. Ausserdem fällt bei den Patienten sofort eine Störung der Sprache auf, welche einerseits das Spracbvermögen. andererseits das Verständniss für das gesprochene Wort betrift. Soweit sich dies bei dem anscheinend wenig intelligenten Patienten feststellen lässt. handelt es sich einmal um eine Paraphasie. indem der Kranke beim Sprechen vielfach neugebildete, unverständliche Worte vorbringt und auch eine Reibe vorgehaltener Gegenstände mit solchen neugebildeten Ausdrücken belegt, trotzdem er dieselben offenbar als solche richtig erkennt und ihre Benutzung anzudeuten vermag. Andererseits versteht er aber auch eine Reihe von Worten und Fragen, die man an ihn richtet, absolut nicht, giebt ganz verkebrte Antworten und vollführt von ihm Verlangtes nicht, während er einzelne andere Fragen richtig versteht und beantwortet und Geheissenes auch richtig ausführt. Störungen beim Lesen und Schroiben lagen nicht vor. da Patient weder lesen noch schreiben gelerrit hatte. Im Uebrigen machte or nicht den Eindruck eines stark verwirten Menschen; anf der Abtheilung orientirte er sich bald, war, so lange man sich mit ihm beschäftigte, aufmerksam und gab sich sichtliche Mähe, sich verständlich zu machen. was ibm in gelungenen Falle stets viel Freude machte. Dabei war er zumeist kindlich heiterer Stimmung. die sich bei Verabreichung eines Glas Weins oder einer Cigarre in stürmischen Heiterkeitsbezeugungen Luft machte.

In den nächsten Monaten bot der Kranke keine Veränderungen dar; er blieb zumeist heiter und vergniigt, war bei der Visite sebr redselig. wobei er die durch die Sprechstörung bedingten Mängel durch lebhaftes Mienenspiel auszugleichen suchte. Die rechtseitige Parese besserte sich allmälig, so dass das Schleppen des rechten Beines verloren ging.

Im Juli stellte sich vorübergeherd eine Erregung ein; er schimpfte und schrie sehr viel, verweigerte die Nabrung und drängte nach Hause.

10. December. Leichter apoplectiformer Anfall. Patient ist ziemlich stark benommen und die rechte Seite, einschliesslich der unteren Gesichtsbälfte, gelähmt. Rechte Pupille weiter als die linke; Lichtreaction sebwach; rechts Fehlen des reflectorischen Lidschlusses. 
13. December. Patient ist wieder klarer; er kann mit Unterstützung gehen, doch schleppt er das rechte Bein noch naoh; ebenso benutzt er den rechten Arm nur wenig. Rechter Mundwinkel steht tiefer; die Zunge rermag er noch nicht vorzustrecken. Rechte Pupille weiter als die linke; Lichtreaction erschwert. Anscheinend bestebt eine Sehstörung, indem Patient im rechten Gesichtsfelde beiderseits nichts za sehen scheint, doch sind porerst genauere Prüfungen noch nicht möglich. Daneben zeigt er eine hochgradige gemischte Sprachstörung, da er einmal kein Wort zu verstehen scheint, andererseits nur einzelne vorgehaltene Gegenstände richtig bezeichnen kann, trotzdem er die Gegenstände als solche richtig erkennt. Ausserdem bringt er auch spontan, trotzdem man offenbar sieht, dass er sprechen will, nur einzelne Worte, wie "Brod", "Cigarre", hervor.

Im Laufe der nächsten Zeit bildete sich die rechtsseitige Parese fast vollständig zurück, doch blieb ein Tieferstehen des rechten Mundwinkels, sowie eine gewisse Ungesohicklichleit des rechten Armes zurück. Die Sprachtörung besserte sich insofern, als Patient sich wieder über alitägliche Dinge rerständlich machen konnte, wobei er alierdings oft neugebildete Worte vorbrachte oder aber bei richtigen Worten verkehrte Buchstaben resp. Silben anwendete, doch war sein Sprachschatz entschieden kleiner als vor dem Anfalle. Desgleichen schien es, als ob er von vorgehaltenen Gegenständen keinen mehr richtig bezeichnen könne, trotzdem er sie als solche richtig erkannte und verstand er Gesprochenes anscheinend gleichfalls viel sohlechter als vorher. Doch machten sich hierbei ziemlich grosse Sohwankungen an den einzelnen Tagen bemerkbar. Die Pupillendifferenz bildete sich zurück, Lichtreaction wurde wieder prompt. Dagegen blieb die Sebstörung bestehen und liess sich nunmehr mit ziemlicher Sicherheit nachweisen, dass es sich um eine rechtsseitige Hemianopsie handle. Im Uebrigen bot er wieder das frübere freundliche, geweckte, kindlich heitere Wesen dar.

23. Juli. Patient sinkt heute Morgen ganz plötzlich nach der rechten Seite hin um. Ins Bett verbracht, ist er vollständig bowusstlos und spielen sich im rechten Arm und Beine allerhand zwecklose Bewegungen ab, während der Kopf und die Augen nach recbts gedreht sind. Im Laufe des Tages treten auf der ganzen rechten Körperhälfte Zuckungen auf.

24. Juli. Pat. ist immer noch bewusstlos; von Zeitzu Zeit Zuckungen im rechten Facialisgebiete, im r. Arm und Bein. Der rechte Arm wird dabei zumeist in Contracturstellung gehalten, das Bein nicht, doch sind auch hier passive Bewegungen erschwert. Der Kopf wird hente beständig nach links gehalten, desgleichen die Augen; lelztere vollführen Nystagmusbewegungen von links bis zur Mittellinie. Die linken Extremitäten sind gelähmt, ob die unteren Aeste des linken Facialis anch gelähmt sind, lässt sich nicht sicher feststellen. Sehnenreflexe beiderseits gesteigert, rechts jedoch mehr. Cremasterreflex fehlt links. Mechanische Muskelerregbarkeit, speciell in beiden Pectorales gesteigert. Temperatur nicht gesteigert.

25. Juli. Im grossen Ganzen derselbe Zustand. Auf der rechten Seite heute weniger Zuckungen als allerhand Bewegungen, die den Charakter des 
Gewollten, des Zweckmässigen an sich tragen. Im linken Arme, der noch gelähmt ist, bei passiven Bewegungen mässiger Widerstand. Pupillen beide gleich, schwache Lichtreaction. Temperatur 36,6.

29. Juli. Die vollständige Bewusstlosigkeit hält in gleicher Stärke an; desgleichen bestehen im grossen Ganzen noch dieselben Störungen; doch wechseln die motorischen Reizerscheinungen auf der rechten Seite in ihrer Form. Kopf und Augenstellung noch nach links..

Temperatur eher subnormal $36,3-36,6$.

Patient wird mit der Schlundsonde ornährt.

1. August. Nachdem sich gestern auch eine vollständige Lähmung der rechten Seite eingestellt hatte, trat heute Nachmittag der Tod ein.

\section{Section (10 Stunden post mortem).}

Schädeldach ziemlich schwer, symmetrisch; Diploe stellenweise sebr reichlich, speciell an den Scheitelbeinen. Dura mater ist über die ganze Convexität mit der Innenfläche des Schädels verwachsen und lässt sich nur mit Mühe loslösen. In der rechten mittleren Schädelgrube und von da aufwärts bis etwa zur Mitte der Scheitelgrube hinaufreichend zeigt die Dura eine bräunliche Verfärbung. Im Sinus longitud. flüssiges dunkles Blut. Die Pia mater jst ziemlich blutreich und zeigt sich über die ganze Convexität hin rauchig, stellenwoise weisslich getrübt und mässig verdickt. Am stärksten sind diese Veränderungen über dem Vorderhirn sowie längs der Medianspalte ausgesprochen. Die linke Hemisphäre erscheint in ihrer hinteren Hälfte kleiner und schmäler als die rechte und ist hier die Oberfläche des Gehirns ensprechend dem unteren Scheitelläppchen sowio dem Uebergangstheile in den Schläfenlappen erheblich eingesunken. Die Pia ist über dieser eingesunkenen Partıe ganz erheblich verdickt und überzieht als schlaffe faltige Docke die bier offen bar erweichte Gehirnmasse. In gleicher Weise ist auch ars der mediclen Fiäche der linke Occipitallappen eingesunken and erweicht. Die Gefässe an der Basis zeigea in mässigem Grade atheromatöse Veränderungen. In der rechten Arteria fossae Sylvii findet sich dicht vor der Abgangsstelle des ersten Astes ein fester Thrombus, der das Lumen ganz ausfüllt. Beic Versuche die Pia mater abzulösen bleibt dieselbe an der linken Hemisphäre entsprechend den beiden oben erwähnten Erweichungsherden haften und läss sich bier nur unter Mitnahme von erwejchter Hirnmasse lösen. Man erkennt nun. dass das ganze untere Scheitelläppohen und der hintere Theil der ersten Schläfenwindung in eine röthlich gelbe, schmierige, fast flüssige Masse verwandelt ist. Dieser Herd reicht nach vorne bis an die hintere Centralwindung und ist dieselbe entsprechend ihrem zwBiten unteren Viertel an der hintern, dem Scheitellappen zugewandten Fläche erweicht und verschmälert. Dergleichen sind die unteren Partien der Centralwindungen und des unteren Scheitellappens, welche das Operculum bilden helfen, deutlich verschmälert und zeigen eine etwas höckerige Oberfläche. Der Erweichungsherd an der medialen Fläche des Occipitallappens ist erheblich kleiner und beschränkt sich fast ausschliess- 
lich auf den Zwickel, dabei nur ein wenig auf die angrenzenden Occipitalwindungen übergreifend.

Beim Versuche die Pia von der rechten Hemisphäre loszutrennen, bleiht dieselbe über einem sehr grossen Theile der Convexität haften und lässt sich hier nur mit Losreissung der darunter erweicbten Gehirnoberfäache abzieben. Nach Wegnahne der Pia findet sich ein sehr ausgebreiteter, anscheinend noch ganz frischer Erweichungsherd, der die hintere Hälfte der II., die ganze III. Stirnwindung, die untere Hälfte beider Centralwindungen, den grössten Theil des Scheitellappens sowie die beiden oberen Schläfenwindungen zerstört bat. Es bängt dieser Herd offenbar mit der oben erwähnten Thrombose der Art. fossae Sylvii zusammen.

Die Seitenventrikel sind beide erweitert, speciell die Hinterhörner; das Ependym nicht granulirt. Der link Thalamus opticus ist kleiner und erscheint speciell die Partie des Pulvinar gegenüber rechts sebr deutlich verkleinert und atrophisch. Die Vierhügel lassen keine erhebliche Unterschiede beiderseits erkennen, doch erscheint der linke vordere Vierhügel etwas flacher als der rechte. Desgleichen ist das linke Corpus geniculat. externum etwas flacher als das rechte, während die Optici resp. Tractus optici keinen Unterschied erkennen lassen. An Frontalschnitten ergiebt sich nun, dass der oben erwähnte Herd im linken Scheitellappen die ganze weisse Substanz durchsețt und bis an den Ventrikel heranreicht. Nach hinten zu sendet er einen Ausläufer, der unter der Rinde hin im Marklager bis etwa zur Mitte des Occipitalhirns hinläuft und eine unregelmässige Form zeigt. Derselbe steht jedoch nicht mit dem Erweichungsherde an der medialen Fläche in Verbindung. Der grosse Erweichungsherd der rechten Hemisphäre dringt verschieden weit in die Tiefe, erreicht jedoch nirgendwo die grossen Ganglien resp. die innere Kapsel.

Das Ependym des IV. Ventrikels gleichfalls nicht granulirt. Ein Querschnitt durch den oberen Vierhügel gelegt zeigt, dass die ganze linke Hälfte kleiner und schmäler ist als die rechte und betrifft diese Verschmälerung sowohl dén Fuss als die Haube. Weitere Querschnitte wurden der Härtung wegen nicht angelegt.

Die Pia des Rückenmarkes weist auf der hinteren Fläche eine Reiho Knorpelplättchen auf. Das Rückenmark selbst lässt ausser Blässe und Weichbeit des Gewebes nichts Besonderes erkennen.

Nach der Erhärtung des Gehirns in Müller'scher Flüsssigkeit liessen sich die Grenzen der Erweichungsherde in der linken Hemisphäre - auf den Erweichungsherd in der rechten Hemisphäre, der offerbar ganz frischer Natur war, wurde weiter keine Rücksicht genommen - näher feststellon. Dabei ergab sioh denn auf das Deutlichste, dass der kleinere, an der medialen Fläche befindliche Herd mit dem grösseren nicht zusammenhing. Dieser letztere umfasst das ganze untere Scheitelläppchen sowie die hintere Hälfte der beiden oberen Schläfenwindungen, während das untere Drittel der hinteren Centralwindung sowie die angrenzenden Partie der oberen Scheitelwindungen nor zum Theil, und zwar an den dem unteren Sobeitellappen zugewendeten Partien 
erweicht sind. Im Bereiche des unteren Scheitelläppchens reicht die Erweichung bis an den erweiterten Ventrikel, von dem sie nur durch dünne Schicht getrennt wird. Mehr nach vorne zu, auf einer Frontalebene, die durch das mediale Ende der hinteren Centralwindung gelegt ist, reicht die Erweichung nur mehr wenig in's Marklager hinein, während noch weiter nach vorne, im Bereiche der unteren Partien der hinteren Centralwindung die Erweichung nur die Rinde und die dicht darunter befindlichen Markpartien betrifft. Dio vorderen Hälften der beiden Schläfenwindungen erweisen sich als vollständig intact, dagegen ergiebt sich, dass ein schmaler Ausläufer des Erweichungsherdes nach vorne dringt und hier entsprechend der hinteren Inselregion dio zugehörige weisse Substanz und zum Theil auch noch die Vormauer zerstört hat. Ausserdem ist die letzte Inselwindung erweicht. Bei näherer Uersuchung lässt sich von dem Erweichungsherde aus nach vorne durch das an der Aussenseito des Ventrikels liegende Marklager eine Degenerationszone erkennen; die durch zahlreiche Körnchenzellen charakterisirt ist und vorne, wie auf Horizontalschnitten ersichtlich wurde, offenbar mit dem dreieckigen Markfelde Wernicke's im Zusammenbang steht, das sich nach der Erhärtung schon makroskopisch durch seine gelbliche Färbung als pathologisch verändert erwies.

\section{Mikroskopische Untersuchung.}

Dieselbe erstreckte sich auf den Hirnstamm und geschah in der Weise, dass or von unten nach oben serienweise in Schnitte zerlegt wurde, die in Medulla und Pons möglichst senkrecht zur $A x \theta$, ron da ab nach oben in schräg. horizontalen Ebenen angelegt, theils nach Weigert, theils mit Carmin gefärbt wurden. Eine genauere Durchsicht dieser Präparate ergab nun in den verschiedenen Bahnen und grauen Gebieten folgende Veränderungen. Die Py.bahn zeigt nirgendwo Zeichen einer Degeneration, auch lässt sich eine deutliche Verschmälerung der linken gegenüber rechts nicht nachweisen. Dagegen ist

der linke $\mathrm{Pes}$ pedunculi gegenüber dem rechten deutlich kleiner und schmäler. Es beruht dies rorwiegend darauf, dass der laterale Abschnitt desselben und zwar - bei Hintheilung des Fusses in vier Theile - das äussere Viertel vollständig degenerirt ist und kaum noch eine intacte Nervenfaser anfweist (Fig. 1). Diese Degeneration lässt sich als ein zusammenhängendes Ganze nach aufwärts verfolgen und erscheint auf einer schräg horizontalen Ebene, die etwa parallel dem Verlanfe des Tractus opticus angelegt ist, als hinterster Abschnitt der inneren Kapsel, um in höher angelegten Horizontalebenen allmälig zu verschwinden.

Wie sich an den betreffenden Präparaten sehr schön nachweisen lässt, bängt dieses Degenerationsfeld mit einem hier befindlichen grösseren zusammen. welches sich in dem Winkel zwischen hinterem Ende des Linsenkerns und Pulvinar befindet und dem dreieckigen Markfelde Wernicke's entspricht. Aus diesem grösseren Degenerationsfelde, das durch zahlreiche Körnchenzellen ausgezeichnot ist, lassen sich nun weitere Degenerationszüge in den linken 
Thalam. optic. und zwar speciell in das Pulvinar verfolgen. Das letztere ist, wie schon oben bemerkt, deutlich atrophisch. In den tieferen Schichten desselben bemerkt man fast keine Nervenfasern mehr; dagegen findet sich hier eine reichliche Gliawucherung, die sich stellenweise als derbes, welliges

Fig. 1.

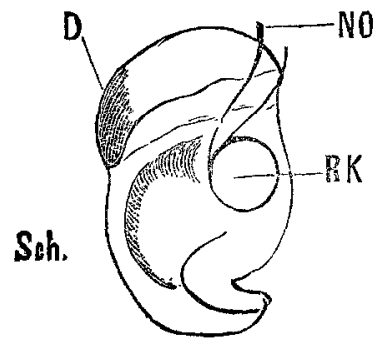

Querschnitt durch den Pedunculus ẗber dem Pons. RK. rother Kerm. D. Degeneration. Sah. Schleife. NO. Nerrus oculomotorius.

Bindegewebe darstellt und in breiten Zügen das Pulvinar quer durchsetzt. Dagegen lassen sich in der oberen Decksohicht noch ziemlich viel markhaltige Nervenfasern nachweisen, die als directe Fortsetzung des Tractus opticns vielfach zu erkennen sind. Die Ganglienzellen fehlen in den caudalen Partien des Pulvinar fast gänzlich, dafür finden sioh Körnchenzellen und ziemlich zahlreiche und zellige Elemente sowie Spinnenzellen.

Das rechte Pulvinar erweist sich als unverändert.

Das linke Corpus geniculatum externum ist fast vollständig von Körnchenzellen durchsetzt und lässt eine anscheinend hyaline Degeneration eines Theiles seiner Ganglienzellen und zwar der lateralen Gruppe erkennen. Daneben findet sicb Wucherung der Gliasubstanz, Verdiekung der Gefässwandungen, während die einstrahlenden Fasern des Tractus ein normales Aus. sehen zeigen.

Das linke Corpus genioulatum internum lässt seine umscheidende Hülle von Nervenfasern als jntact erkennen; desgleichen bemerkt man noch eine grössere Anzahl. offenbar rom Tractus herstammende normal aussehende Nervenfasern, welohe dasselbe durchziehen. Dagegen sind die Ganglienzellen theils geschwunden, theis in ähnlicher Weise wie im Corpus genic. externum verändert und finden sich dafür zablreiche Körnchenzellen vor. Desgleichen fehlen die feinen Nervenfasernetze, welche die Zellen umspinnen. Auf Querschnitten durch die vordere Vierhügelgegend und noch etwas weiter abwärts findet sich dann ein schmales Degenerationsfeld, welches dorsal vom Fusse an der lateralen Seite des Querschnittes liegt und dem linken unteren Vierhügelarme entspricht. Die Nervenfasern zeigen zum Theil Zerfall der Marksobeide, zum Theil sind sie sehr zart und finden sich hier ausserdem ziemlich zahlreiche Körnchenzellen (Fig. 1 q. p.).

Die vorderen Vierbügel lassen makroskopisch keinen deutlichen Un- 
terschied erkennen. Bei der mikroskopischen Untersuchung fällt auf, dass die oberflächliche Deckschioht von Nervenfasern links nur wenig feine Fasern aufweist, und dass sich diese Schicht an Carminpräparaten stärker roth färbt als rechts, was wahrscheinlich durch die anscheinend stärkere Spinnenzellenund Gliawucherung bedingt sein sein dürfte.

Die Schleifenschicht ist überall sohön entwiokelt und lassen sich insbesondere auf beiden Seiten keine anffälligen Unterschiede erkennen.

Auch im Bereiche der $\mathrm{H}$ a u be finden sich keine ausgesprochenen $\operatorname{deg} \theta-$ nerativen Veränderungen, trotzdem die linke entschieden schmäler als die rechte ist.

Desgleichen orweist sich die Substantia nigra beiderseits schön entwickelt.

Von der Mitte des Pons ab lassen sich Grössenunterschiede zwischen den beiden Hälften nicht mehr nachweisen und finden sich weder hier, noch in tieferen Schichten resp. im Rückenmark irgend welche degenerative Veränderungen.

\section{P. Beobachtung.}

Fläsch Lorenz, 72 Jahre alt, ledig; aufgenommen am 6. April 1888, gestorben am 5. Januar 1890.

Der Kranke, der sich in einem Spitale Strassburgs seit längerer Zeit als Pfründner befand, wurde Anfang Februar 1888 von einem apoplectischen Anfalle befallen. Die Sprache war darnach sehr erschwert, besserte sich aber bald darnach; ob Lähmungen vorhanden gewesen waren, blieb ungewiss. Etwa 14 Tage nachher wurde er ängstlich, unruhig, schrie oft lant auf und zerstörte in seinen Erregungszuständen Mobiliar. In Folge dessen kam er in die Irrenklinik nach Strassburg, von wo er nach Stephansfeld transferirt wurde. Bei der Aufnahme bot er folgenden Status dar: Ziemlich gut genährtes, aber ziemlich schwaches und hinfälliges Individuam, dessen Schädel etc. keine auffällige Configuration darbietet. Pupillen gleich, aber sebr enge; Reaction prompt. Der rechte Mundwinkel etwas tiefer stehend. Zunge liegt gerade im Munde und wird gerade vorgestreckt. Der Gang ist unbeholfen bei vornüber gebeugter Haitung, und kraftlos; es besteht jedoch keine Lähmung. In der Ruhe treten an den einzelnen Fingern und im Gesichte vereinzelte fibrilläre Zuckungen auf; bei Bewegungen der Hände deutlicher Tremor. Patellarreflexe beiderseits deutlich. Schmerzempfindung nicht herabgesetzt. Patient hört ganz gut, versteht auch anscheinend das Meiste ron dem, was man zu ihm spricht und kommit Aufforderungen nach. Dabei tritt das Symptom dos Haftenbleibens einer Vorstellung, einer Aufforderung sehr deutlich hervor. Das Sprachvermögen ist erhalten; Patient spricht spontan ziemlich deutlich and verständlich und vermag auch Vorgesagtes richtig nachzusprechen. Dagegen bringt er einmal beim Sprechen allerhand selbstgebildete Worte vor, die öfter einen Anklang an die richtigen zeigen, sodann aber vermag er fast keinen vorgehaltenen Gegenstand richtig zu bezeichnen, troizdem or durch Andeu- 
tungen anzugehen weiss, dass or die betreffenden Gegenstände als solche richtig erkennt. Lese- and Schreibübungen führten trotz mehrfacher Versuche zo keinem Resultate, da der Kranke stets behauptete, er könne dazu nicht mehr sehen. Im Uebrigen machte er auch einen geistig geschwächten Eindruck and warde er, sowie man sich karze Zeit mit ibm abgegeben hatte, rasch müde und unaufmerksam. Doch war er keineswegs verwirrt, sondern wusste sich, sowie es gelang, seine Aufmerksamkeit rege zu halten, ganz gut ụber einfache Dinge zu verständigen. Desgleichen zeigte er sich bald übor seine Umgebung gut orientirt, erkannte den Arzt, die Wärter ete. und war diesen gegenüber meist sehr freundlich.

In der nächsten Zeit blieb der Zastand des Patienten unverändert bostehen. Er zeigte ein ruhiges, harmloses, zumeist apathisches Verhalten, konnte stundenlang regungslos auf demselben Flecki sitzen, hielt sich aber sonst äusserlich geordnet and blieb auch reinlich. Die Sprachstörang zeigte gelelegentlich sehr deutliche Schwankungen, wobei sich anch die Fähigkeit, Gesprochenes za verstehen, an einzelnen Tagen schlechter als an anderen erwies.

25. September. Pat. wird heute früh bei der Visite ziemlich benommen angetroffen und kann er sich nur sehr unsicher und kraftlos fortbewegen. Die rechte Seite scheint etwas paretisch zu. sein und fehlt hier der Cremasterreflex. Desgleichen Patellarreflox rechts sobwächer als links. Patient versteht anscheinend gar nichts und bringt spontan nur einzelne, ganz unverständliche Worte vor. Die linke Pupille ist etwas weiter als die rechte; Lichtreaction sebr träge; auf dem rechten Auge fehlt der reflectorisshe Lidschluss.

27. September. Heute etwas freier; Gang besser und sicherer. Rechtsseitige Parese weniger deutlich. Reflectorischer Lidreflex fehlt auch beute noch rechts und scheint es. als ab Patient im rechten Gesichtsfelde beider Augen nichts sähe. Genaue Prüfungen bei dem geistig schwerfälligen und noch leicht benommenen Patienten nicht möglich. Auch eine genauere Untersuchung der Sprachstörung noch nicht möglich.

1. October. Heute psychisch frei, doch fällt immer noch eine grosse geistige Langsamkeit und Schwerfälligkeit auf. Er verstebt heute einen Theil dessen, was man zu ihm sagt, richtig und kommt auch einzelnen Aufforderungen richtig nach; andere dagegen scheint er absolut nicht zu verstehen. Spontan vorgebrachte Worte sind zumeist richtig, doch laufen, sowie er in etwas längerer Folge spricht, paraphasische Wortbildungen unter. Desgleichen gelingt es ibm meist nicht mehr, dem Sinne und Inbalte nach richtige Satzbildungen vorzubringen; er fängt meist z. B. auf Fragestellungen eine Antwort richtig an, bringt aber dann allerband ungebörige oder neugebildete Worte vor oder bleibt stecken und fängt einen neuen Satz an. Vorgebaltene Gegenstände weiss er absolut nicht richtig zu bezeichnen, trotzdem or sie richtig erkennt. Vorgesprochene Worte vermag er zum Theil ganz richtig nachzusprechen, andere hingegen scheint er absolut nicht zu verstehen. Leseund Schreibübungen lassen sich nicht vornehmen. Die rechte Parese ist nicht mebr nachzuweisen, doch ist rechter Cremasterreflex noch deutlich schwächer als links. Linke Pupille noch etwas weiter als die recbte, Lichtreaction träge. 
Reflectorischer Lidschluss ist heute rechts wieder vorhanden; desgleichen lässtsich ein Gesichtsfeldafect heute nicht nachweisen.

In der Folge nehmen nun die geistigen Funetionen bei dem Patienten langsam, aber stetig immer mehr ab, doch liess sich, wenn auch schwieriger und nicht mehr so deutlich, die eben näher beschriebene Art der Sprachstörung auch später noch feststellen. Der Kranke wurde sehr hinfällig, unreinlich und bekam sehr leicht geschwollene Füsse, so dass er später davernd das Bett bäten musste. Im Uebrigen traten aber keine neuen Störungen hinzu; insbesondere fehlten bis zum Tode motorische und, soweit sich dies nachwoisen liess, sensible Lähmungserscheinungen und schien auch bis zum Endo keine eigentliche Sehstörung aufgetreten zn sein. Nachdem sich gegen Ende December 1889 Decubitus eingestellt batte, starb er am 5. Januar an Marasmus.

\section{Section (14 Standen post mortem).}

Schädeldach ziemlich dick und sehwer, symmetrisch; tiefe Gefässfurchen, wenig Diploo. Die Innenfläche der Dura zeigt über die ganze Convexität hin einen mehrschichtigen, bräunlichen Belag; desgleichen in den Schädelgruben, doch finden sich hier in den vorderen und mittleren Schädelgruben noch kleinere, frischere Blutungen in der Neomembran. Die Pia mater ist über die Convexität hin schwach grau weisslich gefärbt und ödematös, am stärksten sind diese Veränderungen über Stirn und Centralhirn ansgesprochen. Gefässe an der Basis stark geschlängelt und durchweg atheromatös entartet. Die Windungen zeigen normale Anordnung und sind im Bereiche des Stirnhirns etwas verschmälert. Seitenventrikel ziemlich erweitert; der linke enthält reichliche Menge rötblich gefärbter Flässigkeit. Ependyn ganz fein granulirt. Bei Frontalschnitten erweist sich die Rinde im Bereich des Stirnhirns verschmälert and ziemlich blass. Bei einem Frontalschnitt, der hinter den grossen Ganglien durch die linke Hemisphäre gelegt wird, trifft man auf einen ziemlich ausgedehnten Erweichungsherd, der einerseits bis nahe an die Ventrikelwand herangeht, andererseits mit seinen zungenförmigen Ausläufern bis in die Marksubstanz der ersten und zum Theil auch der zwoiten Schläfenwindung hineinreicht, die Rinde dieser Windungen jedoch intact lässt.' Ein anderer Ausläufer dringt in einer frontalen Höhe von ungefähr $2 \mathrm{Ctm}$. nach vorne $z$ wischen Linsenkern und Insel und hat hier die äussere Capsel, sowie oinen Theil des Claustrums im Bereiche der zwei letzten Inselwindungen anscheinend zerstört. Die Rirde selbst scheint nirgendwo zerstört zu sein, doch ist der Uobergangstheil des Gyrus angularis in die erste Schläfenwindung etwas verschmälert und die Oberfläche desselben etwas böckerig. Ein woiterer Frontalschnitt, $2 \mathrm{Ctm}$. hinter dem eben erwähnten angelegt, trifft bereits das bintere Ende des Erweichungsherdes. In der rechten Hemisphüre findot sich gloichfalls ein etwa kirschkerngrosser Erweichungsherd; derselbe nimmt in einer Frontalebene, die etwa durch die Mitte des T'uberculum anter. des Sehhügels gelegt ist, den Schwanzkern ein und sendet einen schmalen Forisatz quer durch die innere Capsel zur oberen Spitze des Linsenkerns (Fig. A.). Die Gebirnsubstanz ist im Uebrigen ziemlich feucht, wenig blutreich und lässt 
speciell in den vorderen Hirnpartien ziemlich viel Gefässquerschnitte in der weissen Substanz erkennon. Ependym des vierten Ventrikels granulirt. Kleinhirn, Pons, Medulla and Rückenmark bieten makroskopisch nichts Besonderes.

Nach der Erhärtung in Müller'scher Flüssigkeit liessen sich die Grenzen des Herdes genauer feststellen und ergab sich hierbei auf den versebiedenen Frontalebenen eine Localisation und Ausdehnung desselben, dio sich am besten aus den folgenden Abbildungen erkennen lässt. Man sieht auf Fig. B.,
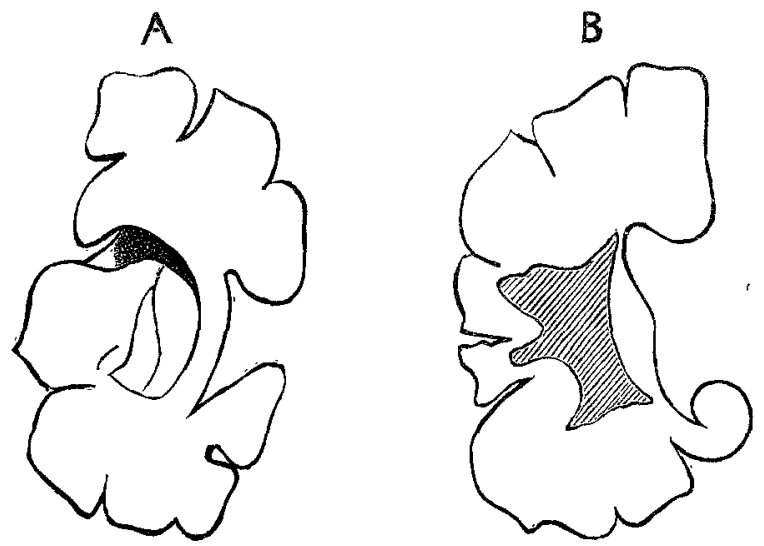

die einem Frontalsohnitte durch die Uebergangsstelle des Gyrus angularis in die erste Schläfen windung entspricht, dass der Herd sicb überall auf die weisse Marksubstanz beschränkt. Nach jnnen zu reicht er an seiner oberen und unteren Grenze bis nabezu an die Ventrikelwand heran, lässt aber dazwischen die dem Ventrikel anliegende weisse Substanz mehr oder weniger intact. Nach a ussen sendet er je einen zungenförmigen Fortsatz in die Uebergangswindung zwischen erster Schläfenwindung und G. angularis, sowie in den betreffenden Theil der zweiten Schläfenwindung hinein, der das Windungsmark zum Theil zerstört bat, die Rinde aber unversehrt lässt. Der Schnitt ist so gefallen, dass er gerade durch den binieren Absehnitt des Herdes geht, so dass ein $1 \mathrm{Ctm}$. weiter nach hinten angelegter Frontalschnitt nichts mehr von dem Herde erkennen lässt. Figur C. entspricht einer Froutalebene, die etwa 2 bis $3 \mathrm{Ctm}$. por der in Fig. B. dargesteliten liegt. Wie man sieht, ist der Herd bereits viel kleiner geworden und stellt einen relativ sohmalen Spalt innerhalb der weissen Substanz dar, der dicht an die Rinde der Inselwindung heranreicht, letztere aber intact lässt und der einen Ausläufer in die Marksubstanz der ersten Schläfenwindung hineinsendet. Eir weiterer Frontalschnitt, etwa $2 \mathrm{Ctm}$. vor diesem angelegt, trifft das vordere Ende des Herdes, der hier nur eineu schmalen Spalt zwischen Linsenkern und Inselwindungen darstellt und eine frontale Höbe von etwa $1 / / 2 \mathrm{Ctm}$. hat. 


\section{Mikroskapische Untersuchung.}

Eine Untersuchung der linken Hemisphäre vor vollendeter Härtung auf Körnchenzellen ergab folgende Resultate. Innerhalb des normal ausgehenden Markstreifens, der sich allmälig verbreiternd zwischen Ventrikelwand und dem vorderen Ausläufer des Erweichungsherdes lag, fanden sich zahlreiche Körnchenzellen und zwar in den unteren Partien - frontal gedacht - bedeatend mehr als in den oberen. Fig. C. macht dies Verhältniss durch die Stärke der Punctirung bei a deutlich. An horizontalen Schnitten, die an der äusseren Seite ein wenig nach unten schräge verlaufen, liess sich dann feststellen, dass ein breiter Zug ron Körnchenstellen sich ron aussen nach innen hinziøht, der einmal einen Ausläufer zum hinteren Ende der inneren Capsel

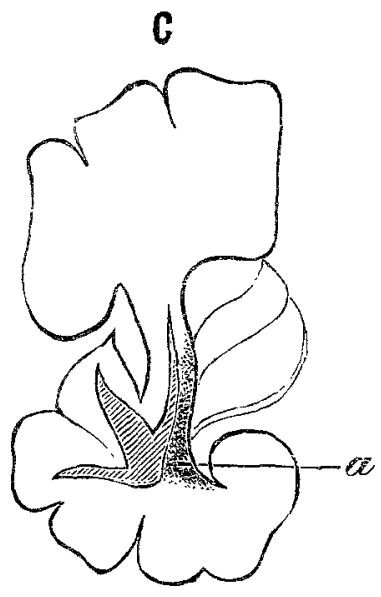

sendet, andererseits unter Einschluss des Corpus geniculat. intern, in die tieferen Schichten des Pulvinar dringt und dasselbe hier auf grössere Ausdehnung hin bis zum medialen Rando durchsetzt, dabei aber die zonalen Partion freilässt. Auf einem Querschnitt durch die Gegend der vorderen Vierhügel finden sich einmal Körnchenzellen im lateralen Abschnitte des Pes pedunculi, sodann in der Gegend, welche dern hinteren Vierbügelarme entspricht. In der rechten Hemispläre lassen sich von dem Herde abwärts innerhalb der inneren Capsel gleiehfalls Körnchenzellen nachweisen und zwar in einem relativ kleinen Abschuitte derselben, der im weiteren Verlaufe nacl abwärts allmälig etwas nacb hinten rückt ind sich schliesslich im zweiton Viertel des Fusses von innen gerechnet vorfindet.

Die genauere mikroskopisehe Untersuchung des Hirnstammes nach der Erhärturg ergab nun folgende Resultate.

Im linken Pes pedunculi ist der laterale Abschnitt degenerirt, jedooh nicht gleichmässig in gleicher Stärke. Während der am meisten nach aussen gelegene Abschnitt noch eine Anzahl anscheinend intacter Fasern aufweist, 
folgt nach innen daron ein Segment, welches eine totale Degeneration zeigt, da hier keine Nervenfaser mehr zu sehen ist. Dieses Segment, welches ungefähr die Gestalt eines Dreieckes hat, dessen breitere Basis der ventrale Rand des Pes bildet, erscheint bei Weigertfärbung fast absolut farblos, während die lateralste Partie noch eine leicht bläuliche Färbung zeigt (Fig. 2).

Fig. 2.

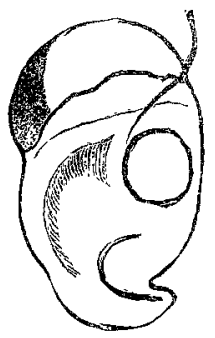

Fig. 3.

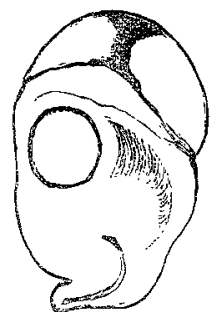

Ein Vergleich mit analogen Schnitten des vorigen Falles ergiebt einmal, dass die degenerirte Zone bei Flesch etwas grösser ist als bei Bey und auf Querschnitten ein wenig weiter nach innen reicht, wio dies auch eine Vergleichung der Fig. 1 und 2 zeigt; andererseits, dass die Degeneration der lateralsten Partien im Falle Bey stärker zu sein scheint als im Falle Flesch, während die intensive Degeneration der mehr medial gelegenen Faserpartien im lateralen Abschnitte, wie sie im Falle Flesch vorlag, bei Bey sich niobt so bemerkbar macht. Diese Degeneration reicht nach unten bis zur oberen Ponsetage und lässt sich nach oben etwa bis zur Mitte des Thalamus verfol. gen, wo sich, wie wir schon oben sahen, ein Zusammenhang mit dem Degenerationsfelde im Stabkranze nachweisen lässt.

Die linke Pyramidenbahn, sowie die medialen Abschnitte des linken Pes pedunculi zeigen keine Spur einer Degeneration.

Im rechten $P \theta S p e d u n c u l i$ fand sich eine Degenerationszone mit fast totalem Schwande der Nervenfasern in der inneren Hälfte des Fusses und zwar, wenn wir den ganzen Fuss in vier Viertel eingetheilt denken, innerhalb des zweiten inneren Viertels, dasselbe nicht ganz ausfüllend (Fig. 3). Das Degenerationsfeld hat eine dreieckige Gestalt mit der Basis nach der dorsalen Seite gerichtet. Auf Horizontalschnitten lässt sich dasselbe durch die innere Capsel nach oben bis zu dem kleinen Erwoichungsherde verfolgen, der sich vom Streifenhügel zum Linsenkerne hinzieht. Sonst erweist sich der Fuss vollständig frei von jeder Veränderung.

Das linke Pulvinar lässt in seiner Deckschicht, speciell in den caudalen Abschnitten, noch ziemlich viel Norvenfasorn erkennen; dagegen findet sich in den tieferen Schichten ein grosses Degenerationsfeld, welches gleichfalls mit dem Degenerationsbezirk in dem Stabkranz zusammenhängt. Lässt man das Corpus geniculatum internum die Grenze bilden zwischen Pulvinar und Thalamus opticus, so erscheint das ganze Pulrinar mit Aus- 
nahme der peripheren Schicht degenerirt. Es fehlen hier fast alle Nervenfasern, desgleichen findet sich liaum noch eine normal aussehende Ganglienzelle mehr ror; das ganze Gewebe erscheint wie im Zerfall begriffen und finden sich neben zablreichen Körnchenzellen, faseriges Zwischengewebe, reichliche rundzellige Elemente und Verdickung der Gefässwandungen. In den mehr candalen Partien sind die Veränderungen weniger hochgradig und begegnet man hier auch noch normal aussehenden Ganglienzellen.

Das linke Corpus geniculatum internum ist in ähnlicher Weise degenerirt. Auch hier erscheint Alles im Zerfall begriffen und finden sich zahlreiche Körnchenzellen, rundzellige Elemente, verdickte Gefässwandungen und fast keine normal aussehende Ganglienzellen. Desgleichen fehlt das zarte Netz von Nervenfasern, das die Ganglienzellen umspinnt, fast vollständig, wäbrend die compacteren Nervenfaserzüge, welche das Ganglion durchsetzen, erhalten geblieben sind. Desgleichen sind auch die nervösen Faserzüge, welche das Ganglion umscheiden, ziemlich erhalten und an Weigertpräparaten deutlich zu sehen.

Das linke Corpus geniculatum externum erweist sich bei der mikroskopischen Untersuchung als vollständig intact und zeigt nirgendwo eine degenerative Veränderung. Insbesondere sind auch die Ganglienzellen der lateralen Zellengruppen sehr schön entwickelt. Desgleichen lässt auch der linke Tractus opticus nichts Besonderes erkennen.

Leider liessen sich keine vollständige Schnitte durch die vordere Vierhügelgegend anlegen, da bei der Section ein schräger Scbnitt durch diese Gegend gemacht worden war. Immerhin aber liess sich mit Sicherheit nachweisen, dass die Gegerd, welche dem unteren Vierhügelarm entspricht, links viel ärmer an Nervenfasern war, als rechts und dass ausserdem die vorhandenen Fasern stellenweise gegenüber rechts sehr fein und zart waren. Im Zusammenhang mit der weiteren Thatsache, dass sich hier bei der Untersuchung am balbgehärteten Präparate Körnchenzellen nachweisen liessen, dürfen wir wohl mit Sicherheit annehmen, dass auch in diesem Falle sich eine secundäre Degeneration im unteren Vierhügelarme vorfand, wofür auch die Querschnitte aus dem oberen Theile der unteren Vierhügelgegend sprechen. Ob Unterschiede in der Grösse der Ganglien beider vorderen Vierhügel bestanden, liess sich nicht feststellen. Dagegen erschien das linke Ganglion der unteren Vierbügel deutlich ein wenig kleiner als das rechte, ohne jedoch mikroskopisch auffällige Veränderungen der Zellen etc. erkennen za lassen. Desgleichen liessen sich auch noch hier im linken unteren Vierhügelarm die oben"erwähnten degenerativen Veränderungen nachweisen.

Wie im vorigen Falle erwies sich auch hier die Schleife, die Substantia nigra, der rothe Kern linkerseits als ganz normal; desgleichen liessen sich rechts, abgesehen von der oben erwähnten Degeneration im Pes pedunculi, nirgendwo pathologische Veränderungen erkennen.

Die beiden vorstehenden Fälle, welche sich in mancher Beziehung sehr schön ergänzen, bieten sowohl in klinischer, als auch in patho- 
logisch-anatomischer Beziehung mancherlei Bemerkenswertles dar. Wenn wir vorerst auf die uns hier vorwiegend interessirenden anatomischen Befunde näher eingelıen, so liegt das Interesse derselben darin begründet, dass in beiden Fällen nach Zerstörung gewisser Gehirnabschnitte in tiefer gelegenen Hirnpartien secundäre Veränderungen aufgetreten waren, welche einen innigen Zusammenhang und eine directe anatomische Verbindung dieser Gehirnregionen unter einander erkennen lassen. Resumireu wir die anatomischen Befunde in aller Kürze, so fanden wir in dem Falle Bey einen Erweichungsherd in der linken Hemisphäre, welcher das Occipitalhirn - wenigstens in seinen Markstrahlungen -, den hinteren Theil der zwei oberen Schläfenwindungen, das untere Scheitelläppchen, die unterste Partie der hinteren Centralwindung, die letzte Inselwindung, sowie einen grossen Theil des dazwischen ljegenden weissen Marklagers zerstört hatte. Neben diesen Veränderungen liessen sich nun in tiefer gelegenen Hirnabschnitten Veränderungen im lateralen Abschnitte des linken Pes pedunculi, im linken Pulvinar, Corpus genicul. intern. und extern., in dem vorderen Vierhügel und dem linken unteren Vierbügelarm nachweisen, die offenbar secundäre waren und in Folge der durch die Erweichung gesetzten Zerstörung gewisser Centren und Leitungsbahnen zur Entwickelung gekommen waren. Im zweiten Falle nahm der Erweichungsherd einen viel kleineren Umfang ein und beschränkte sich, wie wir sahen, ausschliesslich auf das weisse Marklager, die graue Hirnrinde überall intact lassend. Seiner Lage nach mussten die Markstrahlungen der ganzen ersten, zum Theil auch der zweiten Schläfenwindung, ein grosser Theil der Markstrahlungen aus dem Hinterhauptslappen und dem unteren Scheitellappen unterbrochen resp. zerstört sein; desgleichen noch Faserzüge, die von der hinteren Inselgegend herrührten. Auch hier fanden sich nun Veränderungen in tiefer gelegenen Hirnabschnitten, die offenbar gleichfalls secundärer Natur waren und zwar wiederum im lateralen Abschnitte des linken Pes pedunculi, im linken Pulvinar, im linken Corp. genieul. intern. und unteren Vierhügelarm, während das Corp. genicul. externum sich bier vollständig normal verbielt.

Wir finden demnach in beiden Fällen gemeinsam eine Degeneration im Pes pedunculi and zwar im lateralen Abschnitte desselben. Dieselbe war, wie wir sahen, im Falle Flesch etwas grösser als im Falle Bey und nahm auf Querschnitten etwa den vierten Theil des ganzen Fusses ein. Diese degenerirte Zone liess sich auf schräghorizontalen Schnitten etwa bis zur Mitte des Thalamus hinauf verfolgen und stand, wie wir sahen, mit einem Degenerationsfelde im 
"dreieckigen Markfelde" (Wernicke) im Zusammenhang, welches seinerseits wiederum als Durchgangsstation von degenerirten Stabkranzfasern erkannt wurde, die sich bis zu den Erweichungsherden zurück verfolgen liessen. Eine genaue Unterscheidung und Trennung dieser Stabkranzfasern, welche direct zu dem lateralen Abschnitte des Pes pedunculi verlaufen, nach der ihnen zagehörigen Rindenregion, liess sich mit Sicherheit nicht feststellen, da in beiden Fällen Stabkranzfasern sowohl vom Schläfen- als auch vom Hinterhaupts- und Scheitellappen unterbrochen resp. zerstört waren und diese Fasern nicht fortwährend getrennt von einander verlaufen, sondern im „dreieckigen Felde" zusammenkommen und sich hier nicht mehr differenziren lassen. Ziehen wir die bis jetzt bekannt gewordenen Beobachtungen von secundärer Degeneration des lateralen Bündels im Grosshirnschenkel zu Rathe, so finden wir darunter nur eine einzige, die in stricter Weise erkennen lässt, welche Stablranzbündel in dem lateralen Abschnitte ibre Fortsetzung finden. Es ist dies die erste Beobachtung von Monakow's, welche derselbe in seiner grösseren Arbeit über die Beziehungen der Sehsphäre zu den infracorticalen Centren*) mitgetheilt hat. Aus denselben geht hervor, dass Stabkranzfasern des Hinterhauptslappens mit dem lateralen Abschnitte des Pes pedunculi in directer Verbindung stehen und hier im äussersten Theile zum Pons hin verlaufen. Leider lässt sich aus der Mittheilung nicht ersehen, welchen Umfang dieses degererirte Bündel im lateralen Abschnitte des Grosshirnschenkels einnahm. Bechterew**) kommt auf Grund seiner Beobachtungen zur Ansicht, dass die Fasern im lateralen Abschnitte mit dem Schläfenlappen und den basalen Theilen des Hinterhauptslappen zusammenhingen, doch geht dies aus dem mitgetheilten Falle keineswegs mit Sicherheit hervor. Auch die übrigen Beobachtungen von Monakow (l. c.), Winkler und Jelgersma**) geben mit Sicherheit keinen Aufschluss über die directen Beziehungen der im lateralen Abschnitte verlaufenden Fasern. Desgleichen dürfte auch der Fall von Sioli $\uparrow$ ) wegen der zu grossen Ausdehnung der Erweichungen nicht beweiskräftig sein und seine Ansicht, dass das laterale Bündel nur Fasern von Schläfen- und ScheitelIappen enthalte, durchaus noch nicht als erwiesen anzusehen sein. Vergleichen wir nun die pathologischen Ergebnisse unserer beiden

*) Dieses Archiv Bd. XVI. Heft 1 und 2.

*) Dieses Archiv Bd XIX. Heft 1.

***) Neurol. Centralbl. 1887. S. 239.

†) Allgemeine Zeitschrift für Psychiatrie. Bd. 45. Heft 4. 
Fälle, so fällt vor Allem der Unterschied des Befundes in dem lateralen Abschnitte des Pes pedunculi auf. Im Falle Bey, wo hauptsächlich der Hinterhauptslappen, wenigstens in seinen Markstrahtungen, sowie die hinteren Abschnitte der zwei oberen Schläfenwindungen zerstört waren, fanden wir die Degeneration auf den lateralsten Abschnitt des Fusses beschränkt; im Falle Flesch dagegen, wo offenbar ein Theil der Stabkranzfasern vom Hinterhauptslappen verschont geblieben war, dagegen gerade die Stabkranzfasem des vorderen Theiles der ersten und zweiten (?) Schläfenwindung zerstört waren, fanden wir einmal die Degenerationszone im lateralen Abschnitte breiter als im Falle Bey, ausserdem aber entsprach die am stärksten degenerirte Zone nicht dem äussersten Abschnitte des Fusses, sondern war etwas nach innen gerïckt. Lassen diese Befunde nun auch die Frage offen, ob Fasern vom Scheitellappen im lateralen Abschnitte des Pes pedunculi vertreten sind, so scheinen sie doch im Hinblick auf die oben angegebenen detaillirten Befunde, sowie im Binblick auf die Beobachtung von Monakow mit grosser Wahrscheinlichkeit dafür zu sprechen, dass die im äussersten Abschnitte verlaufenden Fasern mit dem Hinterhauptslappen, die nach innen daran anstossenden Fasern mit dem Schläfenlappen resp. den oberen Schläfenwindungen in Zusammenbang stehen.

Wie in allen bisher bekannten Fällen von secundärer Degeneration des lateralen Abschnittes des Pes pedunculi ging dieselbe abwärts bis zur oberen Ponsetage, wo sie in den dort befindlichen ventralen Kernen ibr Ende fand. Eine ausgesprochene Verschmälerung und Atrophie dieser Kerne konnte ich in der linken Ponshälfte nicht mit Sicherheit nachweisen, wie dies von Jelgersma (l. c.) in einem ähnlichen Falle geschah, doch liess sich in beiden Fällen, am deutlichsten im Falle Bey, ein geringer Unterschied in der Grösse zwischen den beiden Hälften des Querschnittes bis zur Mitte des Pons ungefähr zu Ungunsten der linken Hälfte constatiren.

Die Pyramidenbahnen erwiesen sich in beiden Fällen vollständig intact, trotzdem im Falle Bey das untere Ende der hinteren Centralwindung erweicht war. Dagegen fand sich im Falle Flesch in der medialen Hälfte des rechten Grosshirnschenkelfusses eine degenerirte Zone, welche ungefähr das zweite Viertel des Fusses, von innen gerechnet, einnahm. Diese Degeneration war secundärer Natur und hing, wie wir oben sahen, von einem kleinen Erweichungsherde $a b$, der den Streifenhügel in der Gegend des Kapselkerns auf eine kurze Strecke hin zerstört, ausserdem aber hier durch einen schmalen Ausläufer die innere Kapsel quer durchtrennt hatte. Es sass demnach 
der Herd ziemlich genau an der Stelle der inneren Kapsel, der ich bereits früher auf Grund von Untersuchungen*) eine besondere Wichtigkeit zuschreiber konnte. Auf Grund von zwei Fällen von Erweichungen, welche die innere Capsel in dieser Gegend an zwei verschiedenen, sich aber gegenseitig ergänzenden Stellen unterbrochen hatte, konnte ich nämlich damals den Satz aufstellen, dass die Faserbündel aus den vorderen Hirnregionen, welche die ganze innere Capsel durchsetzen, die Gegend des Capselknies in dem oberen Drittel (frontal gedacht) passiren müssen. Dieser Satz erhält nun durch unseren Fall Flesch eine Erweiterung dahingehend, dass diese aus den vorderen Regionen stammenden Fasern in der inneren Hälfte des Pes pedunculi ihre Fortsetzung finden. $O b$ und in wie weit die Zerstörung des kleinen Abschnittes des Schwanzkerns an dieser secundären Degeneration Antheil hat, muss ich dahin gestellt bleiben lassen; ebenso muss es unentschieden bleiben, ob die durch den Herd unterbrochenen Faserbündel der inneren Capsel nur Stabkranzfasern des Stirnhirns oder aber auch Fasern vom Streifenhügel enthielten. Was nun die nähere Localisation des Degenerationsfeldes im Pes pedunculi anbelangt, so scheinen der in der oben citirten Arbeit besprochene Fall Schweblin und der hentige Fall Flesch in diesem Punkte nicht vollkommen übereinzustimmen. Es liegt dies aber hauptsächlich daran, dass ich in dem Falle Schweblin - wie ich dies auch damals hervorhob - nicht in der Lage war, vollständige Querschnitte durch den Grosshirnschenkelfuss anzulegen und ich mich aus äusseren Gründen - da bei der Section ein schräg verlaufender Frontalschnitt gerade durch den Pes pedunculi gelegt worden war - auf die Untersuchung partieller Schrägschnitte durch den Grosshirnschenkel beschränken musste. In Folge dessen war es mir damals nicht möglich, die Lage des Degenerationsfeldes ganz genau anzugeben und begnügte ich mich mit der Angabe, dass dasselbe im medialen Abschnitte des Fusses gelegen sei. Unser heutiger Fall Flesch zeigt nun auf das Klarste, dass dieses Degenerationsfeld nicht im innersten Abschnitte des Fusses, sondern mehr nach aussen gelegen ist, so zwar, dass es ungefäbr die Stelle des zweiten Viertels einnimmt, dasselbe jedoch niclıt ganz ausfüllt. Dass es sieh übrigens im Falle Schweblin um Zerstörung ganz analoger Faserbündel des inneren Capsel handeln musste, wie im Falle Flesch, geht deutlic: aus einer Vergleichung der Abbildung B. 5 in der damaligen Abhand.

*) Dieses Archiv Bd. XIX. Heft 3. 
lung mit der heutigen Fig. A. hervor, die beide nach der Natur gezeichnet, die gleiche Lage des Degenerationsbezirkes innerhalb der inneren Capsel unschwer erkennen lassen. Eine gute Uebereinstimmung mit der durch den Fall Flesch gegebenen Localisirung des Degenerationsfeldes liefert übrigens anch der Fall Brink*), bei dem sich gleichfalls trotz Zerstörung der Stabkranzfasern des Stirnhirns eine Degeneration nicht im innersten Abschnitte des Pes pedunculi, sondern mehr nach aussen, etwa im zweiten und dritten Viertel desselben vorfand. Wir werden weiter unten bei Besprechung zweier weiterer Fälle Gelegenheit finden, auf diese Verbältnisse nochmals einzugehen.

Das linke Corpus geniculatum internum zeigte in beiden Fällen einen analogen Befund, und zwar fand sich eine hochgradige Degeneration desselben mit fast vollständiger Zerstörung resp. Veränderung der Ganglienzellen, massenhafter Ansammlung von Körnchenzellen, Nervenfaserschwund, Gefässverdickungen etc. Diese Veränderungen waren, wie wir oben sahen, secundärer Natur, nicht etwa durch die Erweichung primär bedingt, denn sowohl die das Ganglion umscheidenden Nervenfaserbündel waren intact, als auch die gröberen Faserzüge, welche dasselbe durchziehen. Beobachtungen dieser Art scheinen bis jetzt sebr selten zu sein, wenigstens habe ich in der mir zugänglichen Literatur keinen genauer untersuchten Fall von secundärer Degeneration des Corp. genicul. intern. auffinden können. Es drängt sich in Folge dessen die Frage auf, ob diese beiden Fälle etwa einen sicheren Aufschluss darüber geheben können, welche Hirnpartien mit dem Corpus genicul. intern. in näherer Beziehung stehen. Bekanntlich sind die Ansichten der Gehirnanatomen darüber bis jetzt noch sehr verschiedene und widersprechende. Sieht man von der Verbindung des Ganglions mit dem Opticus, die Alle zugeben, ab, so behauptet Wernicke, dass dasselbe durch Stabkranzfasern in directer Beziehung mit der ersten Schläfenwindung und der Inselgegend stehe, eine Ansicht, der auch von Monakow zuzustimmen scheint. Demgegenüber nimmt Flecbsig an, dass Stabkranzfasern vom Hinterbauptslappens mit demselben in Verbindung träten, während Forel jede Verbindung mit Stabkranzfasern überhaupt leugnet. Unser erster Fall Beyer dürfte nun nicht geeignet scheinen, diese Frage zu lösen, da hier durch die Erweichung zu ausgedehnte Zerstörungen gesetzt worden waren, welche nicht nur den Stabkranz des Hinterhauptslappens, sondern auch der ersten Schläfenwindungen und der Insel-

*) Archiv für klin. Medicin Bd. 38 . 
gegend zum grossen Theil unterbrochen hatten. Dagegen dürfte der zweite Fall schon geeigueter sein, etwas Licht auf diese noch dunklen Verhältnisse zu werfen. Wir sahen oben, dass man an geeigneten schrägen horizontalen Schnitten, welche sowohl die erste Schläfenwindung, als auch das Corp. genicul. intern. treffen, einen degenerirten Faserzug ziemlich deutlich von der Gegend der ersten Schläfenwindung resp. hinteren Inselwindungen nach innen hin verfolgen konnte, der in einem nach unten etwas offenen Bogen zum Corpus genicul. intern. und zu den tieferen Schichten des Pulvinar hin zog. Anscheinend handelte es sich hier um directe Verbindungsbahnen des Corp. genicul. internom mit dem Schläfenlappen resp. der hinteren Inselgegend, die in Folge der Zerstörung resp. Ausschaltung dieser Hirnpartien secundär degenerirt wareb. Doch lässt sich dies selbstverständlich mit absoluter Gewissheit nicht feststellen, da man über das "dreieckige Markfeld " hinaus, die einzelnen degenerirten Faserzüge nicht gesondert verfolgen konnte. Immerhin aber dürfte der Fall Flesch mit grosser Wahrecheinlichkeit für die Richtigkeit der Wernicke'schen Annabme sprechen, mit der natürlich auch der Fall Bey übereinstimmen würde. Es spricht bierfür auch noch der Umstand, dass im Falle Flesch ein grösserer Theil der im sagittalen Varke verlaufenden Stabkranzfasern des Hinterhauptes verschont geblieben war, da das Corpus genicul. externum nicht secundär degenerirt war.

Neben der Degeneration des Corpus genicul. intern. fanden sich nun in beiden Fällen noch degenerirte Faserzüge in dem linken unteren Vierhügelarm, die sich bis zum unteren Vierhügel verfolgen liessen. Da das aus dem Corpus genicul. intern. entspringende und im unteren Vierhügelarm verlaufende Faserbündel intact zu sein schien, so dürfte es sich vielleicht um jene Stabkranzbündel handeln, die nach der Angabe Meynert's*) den unteren Vierbügel mit der Grosshirnrinde verbinden sollen. Wäre diese Aunahme richtig, so dürfte man im Hinblick auf den Fall Flesch die weitere Ansicht aussprechen, dass diese Stabkranzfasern höchst wahrscheinlich aus dem Schläfenlappen herstammen, da der erwähnte degenerirte Faserzug sich anscheinend zugleich mit den Fasern, die zum Corpus genicul. intern. hinzogen, vom Schläfenlappen nach innen, zum unteren Vierbügelarm hinwandte.

Jedenfalls dürften die degenerirten Fasern nicht aus dem Corpus

*) Klinik der Erkrankungen des Vorderhirns. 
genicul. internum herstammen, da die Zeitdauer zwischen dem Entstehen der Erweichungsherde und dem Tode nach den bisherigen Erfahrungen viel zu kurz war, um annehmen zu können, dass sich die secundäre Degeneration über das Ganglion hinaus fortentwickelt hätte. Ausserdem wäre es nicht zu verstehen, warum im Falle Bey trotz der Degeneration des Corpus genicul. extern. der Opticus vollständig intact blieb und nicht auch secundär degenerirte, wie dies ja in den Fällen von Monakow, Siemerling, Schmidt-Rimpler bei allerdings viel längerem Bestehen der Erweichungsherde thatsächlich der Fall war.

Das Corpus geniculatum externum zeigte in den beiden Fällen ein verschiedenes Verhalten. Während es, wie wir saben, im ersteren Falle Bey degenerirt war, blieb es im zweiten Falle Flesch vollständig intact. Es hängt dies offenbar mit der verschiedenen Lage und Ausdehnung der Erweichungsherde in beiden Fällen zusammen. Nach den Untersuchungen v. Monakow's und anderer Forscher kann es heute keinem Zweifel mehr unterworfen sein, dass Zerstörung gewisser Rindenpartien des Occipitallappens, und zwar hauptsächlich des Cuneus und der ersten Occipitalwindung oder aber Unterbrechungen der von diesen Hirnregionen berstammenden im sagittalen Marke verlaufenden Stabkranzfasern nach gewisser Zeit secundäre Degeneration gewisser Abschnitte des Corpus geniculat. externum, des Pulvinar und des vorderen Vierhügels herbeiführen. In unserem ersteren Falle finden wir nun thatsächlich ganz in Uebereinstimmung mit dieser Lehre eine Zerstörung des Cuneus sowie eine totale Unterbrechung der im sagittalen Marke dahinziehenden Stabkranzfasern des Occipitalhirns, andererseits secundären Veränderungen im Corpus geniculatum externum, im Pulvinar und im vorderen Vierhügel; jm $z$ weiten Falle Flesch dagegen fehlte einmal jegliche Veränderung im Bereiche des Occipitallappens, andererseits hatte ider Erweichungsherd, wie wir sahen, eine derartige Lage und Ausdehnung, dass ein Theil des sagittalen Markes intact erhalten blieb. Da nun das Corpus geniculatum externum keine Spur einer Degeneration zeigte, so müssen im sagittalen Marke gerade die Fasern verschont geblieben sein, welche vom Occipitallappen her kommend; in diesem Ganglion ibr vorläufiges Ende finden. Es steht somit auch dieser Fall nicht nur in vollem Einklange mit der soeben erwähnten Lehre, sondern er dürfte gerade im Hinblick auf sein negatives Ergebniss hinsichtlich des Corpus genicul. externum ein neuer, gewichtiger Zenge für die Richtigkeit derselben sein.

Die Stabkranzfasern, welche vom Occipitalhirn durch das sagittale 
Mark nach vorne ziehen und in das Pulvinar einstrablen, mussten dagegen auch im Falle Flesch zerstört gewesen sein, da sich hier in den tieferen Schichten des Pulvinar sehr ausgedebnte secundäre Veränderungen vorfanden. Diese Veränderungen waren jedoch entschieden ausgedehnter und nahmen sowohl in horizontaler als in frontaler Richtung einen grösseren Umfang ein als im Falle Bey, wie eine Vergleichung beider Fälle nach dieser Richtung ergab. Es hängt dies anscheinend damit zusammen, dass im Falle Flesch anch noch eine grössere Anzahl von Stabkranzfasern, welche aus der vorderen Schläfen- resp. hinteren Inselgegend kommen und in das Pulvinar einstrahlen, durch den Herd unterbrochen und zerstört worden waren.

In klinischer Hinsicht boten die beiden Fälle gleichfalls manches Interessante dar und war es zu bedauern, dass bei den geistig geschwächten und ziemlich indolenten Patienten genauere klinische Untersuchungen nicht möglich waren. Sieht man von den allgemeinen psychischen Krankheitserscheinungen $a b$, so beherrschten in beiden Fällen Störungen der Sprache das Krankheitsbild. Versuchen wir dieselben etwas näher zu analysiren, so war die Motilität der Sprache in beiden Fällen erhalten und waren beide Patienten bis zu ihrem Tode im Stande, Worte ohne jegliche Störung auszusprechen. Dagegen war bei dem Patienten Bey bereits zur Zeit seiner Aufnahme, bei dem Patienten Flescb jedoch erst nach dem zweiten Anfalle im September die Fähigkeit, gesprochene Worte zu verstehen, eine sehr mangelhafte. Es waren anscheinend nur einzelne Worte und Aufforderungen, deren Sinn die Patienten verstanden, da sie auf die weitaus meisten Fragen ganz verkehrte, unpassende Antworten oder aber gar keine vorbrachten und auf die einfachsten Aufforderungen nicht reagirten. Diese Erscheinung hing keineswegs etwa mit der geistigen Schwäche der Patienten oder ihrer Apathie und Unaufmerksamkeit zusammen, da man sich einmal durch Zeichen und Gesten leidlich mit ihnen verständigen konnte and adererseits aus ihrem ganzen übrigen Verhalten deutlich ersah, dass sie für einige Zeit ganz gut ihre Aufmerksamkeit auf bestimmte Dinge lenken konnten. Ganz charakteristisch für den Umstand, dass die Kranken noch eine gewisse geistige Regsamkeit zeigten, war das Verhalten des Kranken Bey, der jedesmal die Zeichen grösster Freude darbot, wenn er nach verschiedenen Versuchen endlich begriffen hatte, was man ihm durch Zeichen etc. hatte mittbeilen wollen. Anch das sonstige Verhalten der Kranken, ihre Fähigkeit, sich auf der Abtheilung gut zurecht zu finden, die Personen ihrer Umgebung zu erkennen, jhre Beobachtung der Reinlichkeit etc. spricht gegen die Annahme, dass dieselben 
wegen etwaiger hochgradiger geistiger Schwäche oder Apathie nicht im Stande gewesen wären, den Sinn der an sie gerichteten, alltäglichsten Worte zu verstehen. Dieses Symptom der Worttaubheit war, wie wir sahen, bei dem Kranken Bey entschieden ausgesprochener als bei dem Patienten Flesch, doch war dieselbe in den letzten Lebensmonaten auch bei ihm eine fast totale. Bemerkenswerth war bei ihm die Erscheinung, dass die Fähigkeit, Gesprochenes zu verstehen, an den einzelnen Tagen entschiedene Schwankungen zeigte, was offenbar mit dem Allgemeinbefinden zusammenhing. Neben dieser Worttaubheit zeigten beide Kranken eine sehr ausgesprochene Paraphasie, die bei Flesch in der ersten Zeit hauptsächlich dann stark hervortrat, wenn man ihn durch Fragen zu directen Antworten veranlasste, dagegen weniger ausgesprochen war, wenn er spontan, aus sich heraus redete. Später verwischte sich dieser Unterschied und wurde die paraphasische Störung sehr hochgradig. Bei beiden Kranken liess sich ansserdem noch eine Störung nachweisen, die mit der von Freund*) als optische Aphasie bezeichneten Störung identisch sein dürfte. Beide vermochten nämlich vorgehaltene Gegenstände nicht zu bezeichnen, trotzdem sie einmal dieselben als solche richtig erkannten, wie sich aus der richtigen Benutzung der Gegenstände, sowie aus den Versuchen, die Worte zu umschreiben, erkennen liess, andererseits aber die betreffenden Worte in spontaner Rede richtig vorzubringen im Stande waren. Freund führt diese Störung bekanntlich auf Läsionen der cerebralen optischen Leitungsbahnen zurück und ist der Ansicht, dass sie stets von einer cerebralen Sebstörung begleitet sei. Eine derartige cerebrale Sehstörung bot nun auch thatsächlich der erstere Fall Bey dar, bei dem sich, wie wir oben saben, eine rechtsseitige Hemianopsie deutlich nachweisen liess. Dagegen fehlte dieselbe im zweiten Falle Flesch, soweit sich dies mit annähernder Sicherheit feststellen liess, vollkommen. Es gewinnt hierdurch dieser Fall noch ein ganz besonderes Interesse, da er beweist, dass eine Unterbrechung der Leitungsbahnen zwischen. Seb- und Sprachcentrum eintreten kann, ohne dass das eigentliche Sehen dadurch in irgend einer Weise gestört wird. Versuchen wir den pathologischen Befund mit diesen klinischen Symptomen in Einklang zu bringen, so werden wir mit grosser Wahrscheinlichkeit annehmen dürfen, dass diese Unterbrechung zwischen Seh- und Sprachcentrum dadurch zu Stande gekommen war, dass die Verbindungsbahnen des

${ }^{*}$ Dieses Archiv Bd. XX. Heft 1 und 2. 
Occipitalbirns mit der ersten und zweiten linken Schläfenwindung unterbrochen waren und somit die Möglichkeit einer Verschmelzung der optischen Erinnerungsbilder im Hinterhauptslappen mit den ibnen associirten Sprachklaugbildern im Schläfenlappen aufgehoben wurde. Ob diese Unterbrechung der Leitungsbahnen $z$ wischen corticalem Sehcentrum und dem acustischen Sprachcentrum ausreichend ist, um diese als optische Aphasie bezeicbnete Sprachstörung hervorzurufen, muss vorerst wohl noch als hypothetisch hingestellt werden, doch wäre es ja in unserem Falle möglich, dass auch noch andere Associationsbahnen, die rom corticalen Sehcentrum herkommen und zu irgend einem Rindengebiete, das zur Sprache in näberer Beziehung steht, hinziehen, durch den Erweichungsherd unterbrochen worden wären. Wie dem auch sei, soviel stebt wenigstens fest, dass in unserem Falle Flesch die Leitungsbahnen zwischen dem linken corticalen und dem subcorticalen-Sehcentrum, speciell dem C. genicul. extern. erbalten geblieben waren und somit die klinische Thatsache, dass keine Sehstörung in diesem Falle vorlag, auch anatomisch vollkommen ibre Erklärung findet. Ein ganz specielles Interesse verdient dieser Fall Flesch auch noch dadurch, dass die Rinde überall intact war und dass somit ein Fall von optischer Aphasie vorlag, der ausschliess. lich durch Unterbrechung resp. Zerstörung von Leitungsbahnen bedingt war.

Ich habe bisher absichtlich die anderen Symptome der Sprachstörung bei Flesch ausser Betracht gelassen und nur jenen, wenn ich so sagen darf, optischen Theil derselben einer näheren Besprechung unterzogen, weil mir dieser Fall geeignet erschien, den bisher mehr theoretischen Darstellungen über die Art und Entstehung dieser Form der Sprachstörung, wie sie speciell Freund näher entwickelt hat, eine thatsächliche Unterlage zu geben. Ich verzichte darauf noch näher einzugehen, weil die klinische Beobachtung unseres Falles doch zu mangelhaft ist, um mehr als hypothetische Schlüsse nnd Aufstellungen zu gestatten. l)ie Erscheinungen der Worttaubheit lassen sich in beiden Fällen unschwer auf den Sitz und die Ausdehnung der Erweichungsherde zurückführen, da wir in beiden Fällen entweder die erste linke Schläfenwindung oder aber doch ihre Stabkranzfasern zerstört fanden. Ebenso dürfte das Feblen jeglicher motorischer Sprachstörung in beiden Fällen nicht weiter auffallen, da ja in beiden Fällen die dritte linke Stirnwindung sammt den zugehörigen Markstrablungen intact gebliebeu war. 


\section{B. Beobachtuno.}

Ww. Foltz, 68 Jahre alt, Tagnerin. Aufgenommen am 21. Juli, gestorben am 21. October 1888.

Die Kranke, über die jegliche anamnestische Angabe fehlte, musste in Stephansfeld aufgenommen werden, weil sie seit einiger Zeit daheim durch ihr beständiges Lärmen und Toben allzu sehr gestört hatte. Bei ihrer Aufnahmo bot sie sich als eine kleine, sehr decrepide und verwahrloste Person dar, die sich in einem Zustande heftiger Aufregung and anscheinend totaler Verwirrtheit befand. Eine nähere Untersuchung ergab, so weit sich dieselbe in der nächsten Zeit anstellen lässt, folgenden Status. Patientin ist auf der rechten Körperhälfte gelähmt; der rechte Arm, der in Beugecontracturstellung gehalten wird, ist vollständig gelähmt, während mit dem rechten Beine in horizontalor Lage noch active Bewegungen möglich sind. Der rechte Mundwinkel stebt tiefer als der linke; Lähmung der unteren Facialisäste, das Verhalten der Zunge kann nicht geprüft werden. Links keine Störung der Motilität. Auf der gamzen rechten Körperbälfte besteht ferner und zwar genau in der Mittellinie abschliessend, eine totale Anästhesie und Analgesie. Der linke Bulbus ist atrophisch, die Cornea total getrübt. Die rechte Pupille ist mittelweit -und starr. Das rechte Ange zeigt eine Sehstörung nnd zwar besteht anscheinend eine rechtsseitige Hemianopsie, soweit sich dies bei der Patientin in ihren ruhigeren Stunden durch Vorhaiten von Esswaaren etc. nachweisen lässt. Daneben zeigt Patientin eine Sprachstörung, die sich allerdings nicht genauer feststellen lässt. Sie bringt zumeist ein ganz verwirrtes Kauderwelsch vor, vermag aber auch noch das balbe Vaterunser ziemlich correct berzusagen. Gesprochenes versteht sie anscheinend nur zum geringsten Theil, da sie nur einzelnen Aufforderungen, wie z. B. die Hand zu reichen, nachkommt. Trotz aller Mühe ist es nicht möglioh, sich ihr über die einfachsten Dinge verständlich zu machen, trotzdem sie in ruhigeren Stunden siohtlich aufmerkt auf das, was um sje ber vorgeht und auch durch Lächeln, lebhafte Gesten zu erkennen giebt, dass sie gewisse Personen wieder erkennt.

Während ihres Aufenthaltes in der Anstalt war sie zumeist in einem Zustande lebhafter Aufregung, sang und schrie stundenlang, war beständig unreinlich, zerriss gelegentlich Betttüoher ote. Dabei war sie in hohem Grade gefrässig. Trotzdem ging sie schliesslich sehr rasch an Erschöpfung zu Grunde.

\section{Section (6 Stunden post mortem).}

Kleines Schädeldach von beinahe rundlicher Form; die rechte Scheitelhöhle geräumiger als die linke. Bei Wegnabme der Dura mater an der Schädelbasis finden sich eine Reihe kleinerer, frischer Blutungen zwischen Dura und Knochen; eine grössere, derartige Blutung findet sich dicht unter dem Foramen occipitale, die sich von hier abwärts zwischen Dura und hinterer Wand des Wirbelcanals fortsetzt und über den unteren Rückenmarksabschnit- 
ten am stärksten ist. Dura mater des Gohirns ist stark gespannt, zeigt aber sonst keine weiteren Veränderungen. Im Sinus longitudinalis reichliches, frisch goronnenes Blut. Pia mater ist über die ganze Convexität hin stark getrübt, längs der Medianspalte verdickt, sonst nicht verändert. Arteria basilaris an einer Stelle aneurysmatisoh erweitert. Die linke Art. fossa Sylvii ist dicht hinter ihrem Abgange von der Carotis int. auf eine 2 Ctm lange Strecke durch einen wandständigen Thrombas verstopft, doch lässt derselbe eine foine Oeffnung, die durcb frisch geronnenes Blat Ferklebt ist, erkennen. An der Spitze des linken Schläfenlappons. am unteren Scheitelläppchen sowle am linken Occipitalbirn lassen sich unter der Pia gelblicho Verfärbongen erkennen und lässt sich dieselbe hier nur noter Lossreissung der darunter liegenden, erweichten Hirnoberfläche wegnehmen. Nach Abzug der Pia findet sich linkerseits ein grosser Erweichungsherd, der die ersie Schläfenwindung ganz, die zweite in ihrem hinteren Abschnitte, den Lobulus ling. und fusiformis, den unteren Soheitellappen sowio die angrenzenden Partien des Hinterhauptslappen umfasst. Ausserdem fühlen sich beide Centralwindungen in ihren unteren Abschnitten, bintere Inselgegend sowie dritte Stirnwindung etwas weich an, zeigen aber weder Aenderung ibrer Conturen noch oine Verfärbung der Oberfiäche. Seitenventrikel nicht vergrössert. In der Mitte des Kopfes des rechten Schwanzkerns ein kleiner oberflächlicher Erweichungsherd. Der linke Thalamus opticus ist speciell in seinem hinteren Abschnitte deutlich Hleiner und flacher als der rechte; desgleichen erscheinen boide Corp. genic. extern. flach und klein. links in etwas stärkerem Grade als rechts. Der linke Opticus dünner als der rechte und ron etwas speckig grauer Farbe.

An Frontalschnition erkennt man, dass die Erweichung an den einzelnen Stellen versobieden weit in die Tiefe geht und im Bereiche des unteren Schoitelläppohens anscbeinend bis dicht an die Ventrikelwand hereinreicht. Der linke Grosshirnschenkel ist deutlich kleiner als der rechte and betrifft dieser Unterschied nicht nur den Fuss, sondern auch die Haube. Querschnitte durch den oberen Theil des Pons lassen noch deutlich eine Verschmälerung der linken Hälfte erkennen; woiter nach unten verliert sich der Unterschied und lässt das Rückenmark anf Querschnitten makroskopisch nichts Abnormes orkennen.

Nach der Erhärtung liessen sich Sitz und Ausdehnung des Erweichungsherdes genauer bestimmen und fanden sich nunmehr Verbältnisse, wie sie die beifolgenden Figuren am besten erkennen lassen werden. Man ersieht daraus, dass die Erweichung im Bereiche des Praecuneus (Fig. D) bis dicht an den Ventrikel heran geht und die untere Hälfte des den Ventrikel begrenzenden Marklagers vollständig zerstört hat.

Ganz abalog liegen die Verhältnisse in der Frontalebene, die durch den oberen Theil der hinteren Centralwindung gelegt ist (Fig. E). Weiter nach vorne geht die Erweichung nur bis an den Linsenkern heran, denselben im Allgemeinen freilassend, doch erkennt man, dass derselbe in seinen hinteren und basalen Partien mit erweicht ist. Die beiden Centralwindungen sind in ihrer unteren Hälfte sammt einem Theil des zagehörigen Marklagers glojch- 
falls erweicht (Fig. F und G), während die dritte Stirnwindung nur wenig gelitten hat. Nirgend wo jedoch reicht der Herả bis an die innere Capsel heran.

\section{Mikroskopische Untersuohung.}

Dieselbe geschah in ganz analoger Weise wie im Falle Bey und beschränkte sich auf den Hirnstamm und das Rückenmark. Dabei ergaben sich folgende Veränderungen.
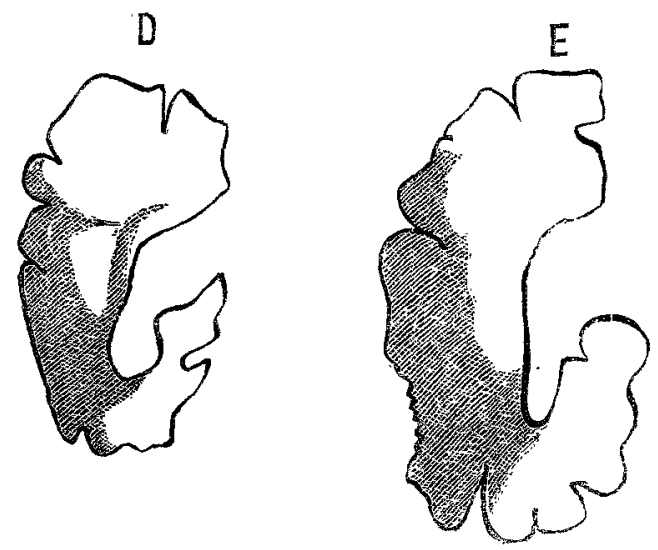

Der linke Pedunculus ist durchweg schmäler und kleiner als der rechte. Auf Quersohnitten dureh denselben in der Gegend dicht oberbalb des
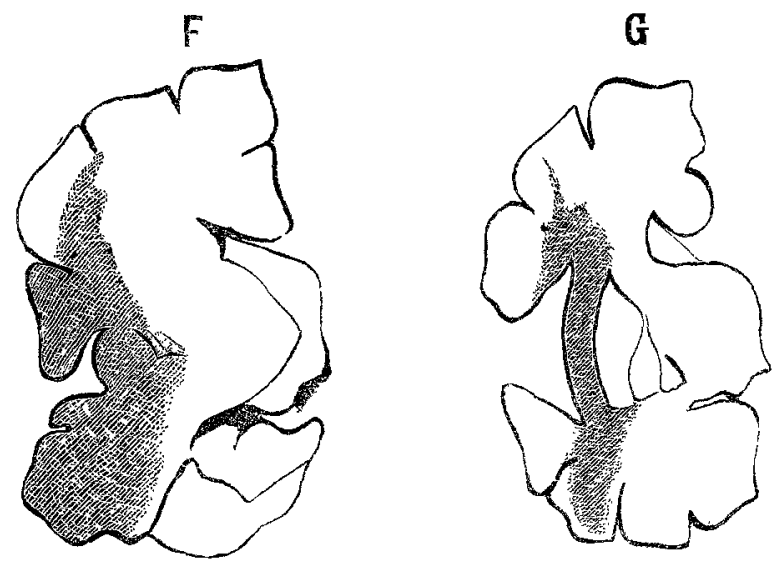

Pons erseheini der Fuss bei Weigertfärbung durchweg heller als der rechte nod ungleich gefärbt. Es beruht dies, wie die mikroskopische Untersuchung 
ergiebt, auf einer Degeneration, welche fast den ganzen Fuss, aber in ungleicher Stärke betroffen hat. Das laterale Viertel ist fast total degenerirt und erscheint hier wieder der änsserste Abschnitt am stärksten betroffen zu sein. Das zweite, der Pyramidenbahn zukommende Viertel zeigt gleichfalls eine Degeneration, doch finden sich bier noch ziemlich viel intacte Nervenfasern vor. In der medialen Hälfte ist der äussere an die Pyramidenbahn anschliessende Abschnitt am wenigsten rerändert, während das innerste Viertel wiederum sebr deutliche und ausgesprochene degenerative Veränderungen aufwoist. Verfolgt man auf Sohräg- resp. Horizontalschnitten den Fuss nach

Fig. 4.

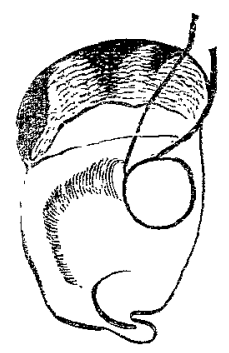

oben weiter, so wird in der Gegend, wo der Grosshirnschenkelfuss in das Gehirn untertaucht, die Beurtheilung seines medialen Abschnittes eine recht schwierige, da hier fortwährend Durchflechtungen und Umlagerungen von Faserbündeln stattfinden, immerhin scheinen aber die Verhältnisse hier dieselben wie in der tieferen Region zu sein. Nach Umwandlung des Fusses in die innere Capsel bildet das Degenerationsfeld ein zusammenhängendes Ganze, das weiter nach oben bin immer kleiner wird and schliesslich anf den hintersten Abschnitt der inneren Capsel beschränkt wird, wie dies die Figuren 5 und 6, die Horizontalschnitten in verschiedener Höbe entsprechen, am besten erkennen lassen. Wie man sieht, ist danach bereits in einer horizontalen Ebene, die dicht über den Opticus gelegt ist, die vordere Hälfte der inneren Capsel vollständig frei von degenerativen Veränderungen, während in einer Horizontalebeno, die der Mitte des Thalamns entspricht, nur noch das letzto Viertel derselben degenerirt erscheint. Nach abwärts lässt sich die Degeneration des medialen und lateralen Abschnittes des Fusses wiederum nur bis zur aberen Ponsetage verfolgen. Die hier liegenden Ponskerne lassen keine dentliche Verschmälernng gegenüber rechts erkennen, doch scheinen in einzelnen Kernen die Ganglienzellen etwas kleiner und von pericellulären Räumen ungeben zu sein; desgleichen ist auch mehrfach das die Zellen umspinnende Netz von feinen Nervenfasern nicht so dicht wie in den entsprechenden Kernen reobterseits. Die Degeneration innerhalb der Pyramidenbahn lässt sich schon makroskopisch am gehärteten Präparate innerbalb der Medulla und der oberen Hälfte des Rückenmarks durch die hellere Färbung deutlich erkennen, wäb- 
rend dies im Bereiche des unteren Dorsal- and des Lendenmarks weniger gut möglich ist. An gefärbten Querschnitten bemerkt man, dass auch im Verlaufo der Medulla und des oberen Räckenmarkes die Degeneration der Pyramidenbahn keine totale ist, sondern dass sich bier neben den degenerirten noch eine ziemliche Anzahl ansclieinend intacter Fasern vorfinden. Je tiefer man im Rückenmarke weiter schreitet, um so mehr nimmt die Degeneration ab, so dass sich an gefärbten Querschnitten und dem Lendenmark die degenerirte rechte Pyramidenbahn kaum noch als solche abhebt.

Fig. 5.

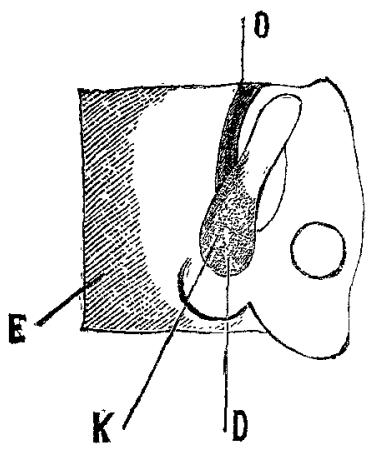

Fig. 6 .

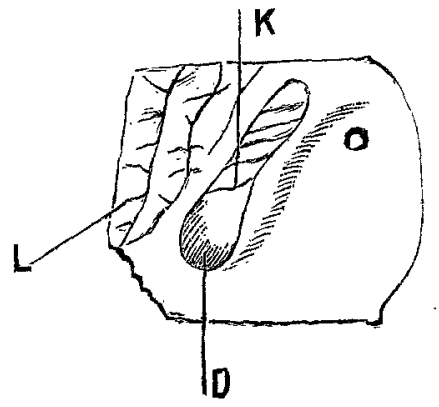

Bchräge Horizontalschnitte darch die basalen Ganglien. E. Erweichung. O. Opticns. D. Serundäre Degeneration, K. Innere Kapse]. L. Linsenkern.

Die Substantia nigra ist links deutlich schmäler als rechts und entbält speciell in ihrem lateralen Abschnitte viel weniger Zellen, die überdies auch zumeist kleiner sind und ein etwas sklerotisches Aussehon zeigen. Ausserdem finden sich hier Körnchenzellen.

Das linke Corpus genioulatum internum ersoheint gegenüber dem rechten kaum verkleinert. Dasselbe ist von zabiroichen Körnchenzellen ganz durchsetzt, so dass man keine irgendwie normale Ganglienzelle mehr zu Gesicht bekommt. Die Nervenfasern, welche dasselbe umscheiden, sind entschioden an Zahl vermindert und durchweg anssergewöhnlich fein und zart. Desgleichen soheinen auch die Nervenfasern, welohe das Ganglion durebsetzen, regressive Veränderungen aufzuweisen. Die austretenden, zum unteren Vier-

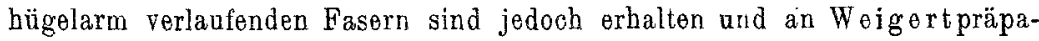
raten schön gefärbt.

Im unteren Vierhägelarm finden sich gleichfalls Körnchenzellen und lassen sich hier bis zum unteren Vierhügel hin neben intacten Fasern solche nachweisen, welche durch zahlreiche Markquellungen grosse Feinheit etc. auffallen und sicherlich als regressiv veränderte anzusehen sind.

Das linke Corpus geniculatum externum zoigt im Bereiche des ventral-medialen Kerns keine erheblichen Veränderungen; einzelne Zellen scheinen atrophisch zo sein, die Mebrzahl jedoch ist anscheinend intact und 
lässt sich auch kein Untersehied hinsichtlich des die Zellen umspinnender Nervennetzes gegenüber rechts constatiren. Dagegen sind die lateralen Kerne hochgradig degenerirt und lassen kaum noch normal aussehende Zellen erkennen; desgleichen finden sich hier wie im medialen Corp. geniculat. zahlreiche Körnchenzellen.

Der linke Opticus resp. Tractus opticus ist zu einem schmalen Streifen zusammengeschrumpft und erscheint auf Längsschnitten beinahe halb so breit als der recbte. An Weigertpräparaten lässt er nur noch vereinzelte normal aussehende Nervenfasern erkennen; daneben finden sich sobr zahlreiche Kerne und rundzellige Elemente sowie chronische Gefässveränderungen.

Auch der rechteTractus opticus zeigt eine deutliche Reduction seiner markhaltigen Fasern; daneben finden sich auch hier zahlreiche Körnchenzellen Fetttröpfchen, Rundzellenvermehrung.

Der linke vordere Vierhügel ist kleiner als der rechte und zeigt das Ganglion desselben eine deutliche Versohmälerung gegenüber rechts. Die dasselbe durchsetzenden Nervenfasern sind entschieden weniger zahlreich als rechts und scheinen auch die Ganglienzellen zum Theil regressive Veränderungen aufzuweisen. In der zonalen Deckschicht fehlen die Nervenfasern fast gänzlich; die vorhandenen sind sehr fein und zeigen vielfach Marktropfen and Markschwellungen. Rechts sind die Nervenfasern der Deckschicht entschioden zahỉreicher und stärker, zeigen aber auch hier und da analoge regressive Veränderungen.

Auch im linken hinteren Vierhiugel ist das Ganglion deutlich kleiner und schmäler als das rechte, doch sind hier die Differenzen in Bezug auf Nervenfasern und Zellen nicht so ausgesprochen wie bei den Ganglien der vorderen Vierhügel.

Auf schrägen Horizontalschnitten, die einer Ebene angehören, welche ein wenig tiefer gelegen ist, als die in Fig. 4 dergestellten, erkennt man neben dem inneren Rande des Fusses und ein wenig dorsal gelegen ein schmales Degenerationsfeld, welches einem Faserbündel angebört, das von vorne her im Bogen gegen den rothen Kern hin zu streben streben scheint. Da sich an den einzelnen Schnitten deutlich nachweisen lässt, dass diese Fasern nicht vom Corpus mammillare herstammen können, so dürfte es sich hier vielleicht um Fasern handeln, die der Linsenkernschlinge angehören, welche nach der Wernjcke'schen Darstellung bier verlaufen soll.

Der linke rothe Kern ist deutlich kleiner als der rechte, lässt aber keine gröberen Veränderungen mikroskopisch erkennen.

Im linken Thalamas finden sich ziemlich verbreitet zahlreiche Körnohenzellen, speciell in den mehr nach hinten gelegenen Partien; das Pulvinar ist bedeutend schmäler und kleiner als das rechte und lässt einen ziemlich ausgedehnten Schwund und Degeneration von Nervenfasern erkennen. Vielfach sind auch die Ganglienzellen verschwunden und sieht man an ihrer Stelle zahlreiche Körnchenzellen.

Die Schleife zeigt keine Veränderung und lässt sich insbesondere auch kein Unterschied derselben zwischen den beiden Seiten erkennen. 
Im Rückenmarke fand sich ausser der oben erwähnten Degeneration im rechten Seitenstrange noch eine dentliche Degeneration der Goll'schen Strärge im Halsmarke, während dieselbe im Dorsal- und Lendentbeil anf die Wurzelregion localisirt war.

\section{Beobachtung.}

Philipps, Ludwig, verheiratheter Zeichner, 44 Jabre alt; aufgenommen am 29. November 1887, gestorben am 8. Jani 1889.

Anamnestisch wurde über den Patienten Folgendes in Erfahrung gebracht. Ausser einem Typhus im 19. Jahre stets gesund bis zum Jahre 1881 . Damals Klagen über Schwindel, Schwerfälligkeit beim Gehen. Am 25. Mai dieses Jahres apoplectischer Anfall; danach Unfäbigkeit za sprechen bei anscheinendem Verständniss für das Gesprochene, sowie Parese des rechten Armes. Keine Lues, wohl aber starke Excesse in potu. Am 30. Mai Aufnahmo in die Irrenklinik in Strassburg, wo er folgenden Status darbot. Pupillen von mittlerer Weite, gleich; keine motorische Lähmung, aber sehr schlaffe Haltung. Patient starrt meist theilnabmlos por sich hin und ist es sehr schwer, vorübergehend seine Aufmerksamkeit zu erwecken. Bald versteht er anscheinend Fragen und kommt an ihn gerichteten Aufforderungen nach, bald nicht. Hin und wieder macht er den Versuch etwas zu sagen, bleibt aber nach wenigen Worten stecken und schweigt dann entweder still oder sagt, Ei, oi“. Vorgesagte Worte nachzusprechen, versucht er meistens gar nicht, thut er es, so bringt er gewöhnlich nur die erste Silbe vor. Eine ophtbalmoskopischo Untersuchung giebt einen negativen Befund. Am 15. Juni lief er fort und wurde er dann pon seinen Angehörigen auf das Land gebracht. Im Jahre 1885 traten anscheinend im Anschluss an Hallucinationen Erregungszustände bei ihm auf; er schrie viel, beschimpfteleute und versuchte sie thätlich anzugreifen. In Folge dessen musste erspäter in dieIrrenanstalt Stephansfeld aufgenommen werden. Hier bot er bei der Aufnahme folgenden Status dar. Kleines, untersetztes und wohlgenährtes Individuum. Linke Pupille etwas grösser als die rechte; Lichtreaction scbwach; rechte Nasolabialfalte flacher als die linke. Der Gang ist nachlässig. schlaff, doch besteht keine motorische Lähmung. Im Uebrigen fällt bei dem Patienten sofort sein auffällig stumpfes, fast antomatenhaftes Verhalten auf. Er steht unbeweglich wie eine Bildsäule, den Kopf etwas zur Seite geneigt und lässt sich weder durch Zureden, Schütteln, noch durch Nadelstiche aus seiner starren Haltung herausbringen oder zu einer sprachlichen Aeusserung veranlassen. Dabei zeigt sein Gesicht zwar einen unbeweglichen, aber doch keinen eigentlich blöden Gesichtsausdruck. Auf der Abtheilung bot or wäbrend der Zeit seines biesigen Aufenthaltes zumeist das gleiohe Verhalten dar. Er stand stunden- und tagelang wie eine Bildsäule auf derselben Stelle und bewegte sich öfter Tags äber nur vom Fleck, um zu Tische zu gehen, wo er ganz ordentlich allein ass oder aber seine Bedürfniss $\theta$ zu verrichten, was or mit grösster Reinlichkeit besorgte. Die versehiedensten Versuche, die angestelltwurden, zu constatiren, ob Patient 
überhaupt börte, blieben resultatlos, da or weder auf Zuruf, noch auf plötzlich in seiner Nähe erweckte Geräusche reagirte. Ebenso wenig gelang es festzustellen, ob irgend eine Sehstörung vorlag. Mit Mühe gelang es ihn durch Zeichen zum Schreiben zu veranlassen, worauf er ganz correat seinen Namen, aber auch nur diesen hinscbrieb. Unerwartete Besuche von Seiten seiner Angehörigen vermochten ebenso wenig ihn aus seiner starren Ruhe hørauszabringen. Dagegen traten zeitreise bei dem Patienten kurze Erregungszuständ $\theta$ auf. Er bekam dann ganz plötzlich und anscheinend unmativirt einen lebhaften Gesichtsausdruck, ballte die Faust und schrie nach eiver Richtung bin "Wart du Kaib, du kriegst es" oder "du Satan, du Saukaib, das ist er". Mit Vorliebe starrte er oft stundenlang in eir Buch, das er zumeist verkehrt in der Hand bielt, deutete dann wohl auch gelegēntlich, wenn man zu ihm herantrat, auf eine besondere Stelle des Buches, sprach aber kein Wort. Anfang Juni 1889 bekam er eine Pneumonie, der or am 8. erlag. Auch während dieser Erkrankung zeigte er das gleiche stumpfe, reactionslose Verhalten und kam kein Wort über seine Lippen.

\section{Section (14 Stunden post mortem).}

Schädeldach ziemlich breit und flach, aber symmetriseh; Duralsack schlaff und weit, onthält ziemlich viel Flüssigkeit; Dura sonst nicht verändert, Pia mater ist über die ganze Convexität hin beiderseits stark verdickt, grauweisslich getrübt und stark byperämisch; ausserdem findet sich fast über die ganze Convexität hin ein 00 dem, das jedoch nicht überall gleich stark ist. Entsprechend dem linken unteren Scheitelläppehen und der hinteren Hälfte der 1. und 2. linken Schläfenwindung ist die Oberfläche des Gehirns eing $\theta$ sunken und spanut sich bier die verdickte Pia ganz lose und faltig über diese Einsenkung hinweg. An der Basis sind die beschriebenen Piaveränderungen nur stellenweise in geringem Grade vorhanden. Die Arteria basilaris ist verdickt, ungleich erweitert und zeigt ebenso wie die Art. fossae Sylvii zum Theil erbebliche atheromatöse Veränderurgen. Die Pia lässt sich überall glatt und ohne Substanzverlust abziehen und bemerkt man nach Abzug derselben an der linken Hemisphäre folgende Veränderungen. Die erste und zweite Schläfenwindung sind in ihren zwei hinteren Dritteln vollständig zerstört und erscheinen dieselben nur noch als schmale leistenartige Wülste. Desgleichen ist der Uebergangstheil beider Sobläfenwindungen in den Scheitellappen zerstört, doch greift dieErweichung weder weit auf die Windungen des Scheitels, nocb auf die des Hinterhauptslappens über. Die 3. Schläfenwindung ist fast vollständig intact und zeigt nur an einzelnen, der 2. Schläfenwindurg zugekehrten Partien erweichte Stellen. Nach vorne erkenns man in der Tiefo der Sylvi'schen Grube, dass mit Ausnahme der 1. und 2. Inselwindung allo übrigen stark atrophisch und vollständig abgeflacht sind, so dass bier der Boden der Sylvi'schen Grube vollständig flach erscheint. Ausserdem ist die letatere wegen der Atrophio der Schläfenwindungen erheblich verbreitert. Die Windungen des Operculums sind nicht wesentlich verändert. Beide Centralwin- 
dungen sowie die 3. Stirnwindung sind äusserlich wohl erhalten und scheinen gleichfalls nicht verändert zu sein. An der rechten Hemisphäre findet sich gleichfalls an dem Uebergangstheile der 2. Sehläfenwindung in das untere Scheitelläppchen resp. 3. Occipitalwindung ein Erweichungherd, wodurch die betreffenden Windungen an dieser Stelle erheblich verschmälert worden sind. Dieser Herd erscheint frischeren Datums als der an der linken Hemisphäro und reicht, wie ein Frontalschnitt ergiebt', nicht tief in das Marklager hinein, so dass das sagittale Mark vollständig verschont geblieben ist. Die Seitenventrikel sind erweitert, das Ependym nicht granulirt. Der linke Thalamus ist speciell in seinem hinteren Abschnitte kleiner nod schmäler als der rechte und erscheinen seine Kanten bier wie zugespitzt. Das linke Corpus genicul. internum ist zusammengeschrumpft und deutlich kleiner als das rechte; desgleichen erscheint auch das linke Corp. genicul. externum in seinem Umfange gegen das rechte dentlicher verschmälert. Der grosse Herd in der linken Hemisphäre reicht in der Gegend des Scheitelläppchens bis an den Ventrikel heran; nach vorne zu ziebt er an derAussenseite desLinsenkerns, den or intact gelassen hat, noch etwa bis zur Mitte des Stirnhirns, wobei er durch verschiedene Ausläufer noch die Markstrahlungen der unteren Abschnitte der Centralwindungen und der dritten Stirnwindung zerstört hat. Beifolgende Abbildungen (Fig. H, J, K, L), welche verschiedenen Frontalschnitten entsprechen, werden dies besser als jede Beschreibung erkennen lassen.
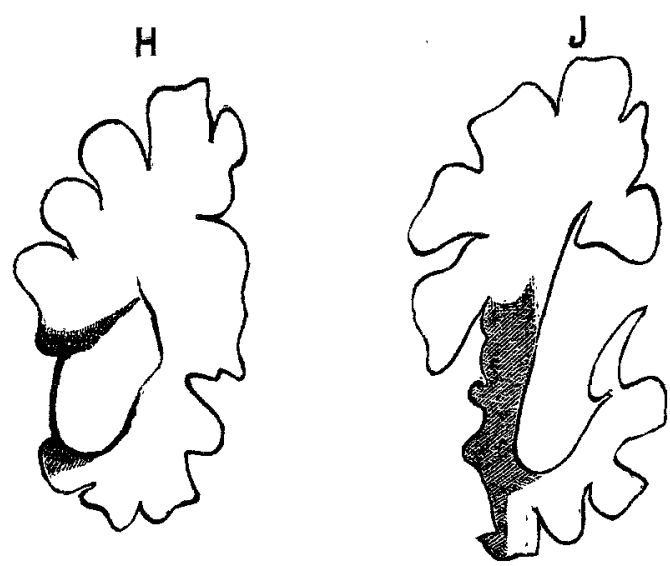

Epeudym des vierten Ventrikels slark granulirt. Der linke Grosshirnschenkel ist in allen seinen Dimensionen schmäler als der recbte; lässt jedooh auf dem Querschnitte makroskopisch nichts Abnormes erkennen. Die linke Hälfte des Pons erscheint auf Querschnitten in der oberen Hälfte gleichfalls etwas schmäler als die rechte. Querschnitte des Rückenmarks lassen makroskopisch nichts Abnormes erkennon. 

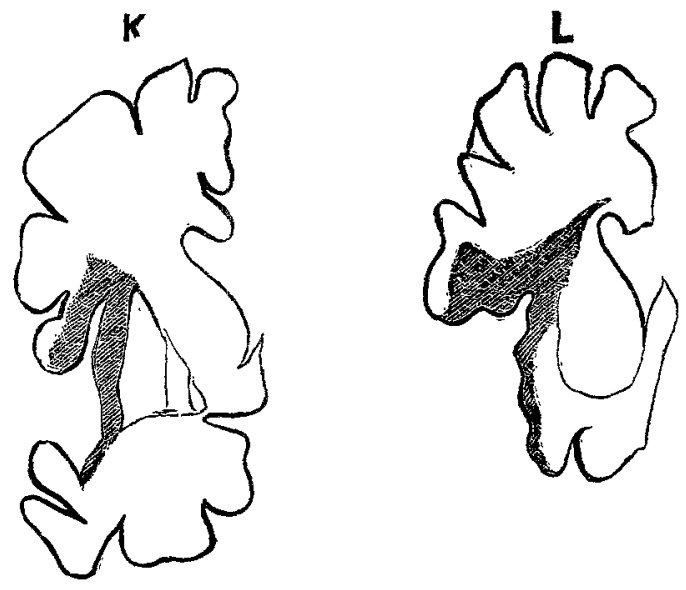

Mikroskopische Untersuchung.

Da ich in diesen Falle untersuchen wollte, ob sich etwa secundäre Degenerationen von der zerstörten Inselgegend her nach abwärts genauer verfolgen liessen. so nahm ich dieses Mal die Untersuchung in der Weise vor, dass ich dio linke Hälfte des Hirnstammes mit Einschluss der zerstörten Inselwindungen serienweise in Frontalschnitte zerlegte, nachdem ich durch einen Querschnitt dnrch den linken Pedunculus dicht ïber dem Pons letzleren abgetrennt hatte, um ihn in gewöhulicher Weise zu untersuchen. Bei Frontalschnitten nun, die darch das hinterste Ende des Pulvinar gelegt wurden, fand sich eine ausgesprochene und ausgedehnte Degeneration der aus dem Stabkranz resp. dem sagittalen Marke in dasselbe einstrablenden Nervenfasern, welche eirse bedeutende Verschmälerung des Pulvinar herbeigefübrt hatte.

Dieses Degenerationsfeld im Stabkranze ging nach aussen bin in die erweichten Partien der Inselwindungen über. Weiter nach vorne, auf Frontalschnitten durch den hinteren Abschnitt des Linsenkerns hat dieses Degenerationsfeld eine nahezu dreieckige Form angenommen, dessen Spitze gegen den Sehläfenlappen und dessen Basis gegen die innere Capsel gerichtet ist (Fig. 7). Dasselbe liegt zwischen innerer Capsel und dem hinteren $A b$ sehnitte des Linsenkerns; der letztere ist intact und scheidet das Degenerationsfeld von der zerstörten Inselgegend. In diesem Degenerationsbezirk treffen einmal Faserzüge, die rom Schläfen- resp. Hinterbauptslappen berstammer, sodann aber zahlreiche Faserzüge, die von der Inselgegend herstammen and den hinteren Abschnitt des Linsenkerns durchsetzen, zusammen. Ein dege. nerirter Faserzug lässt sich anscbeinend von dem seitlichen Winkol des Degenerationsfeldes im Bogen über die Corpora genicn. hin nach abwärts verfolgen: dasselbe biegt in die innere Capsel um and verläuft schliesslich im lateraler Abschnitte das Pes pedunouli weiter. Andere degenerirte Faserzüge konnte 
man deutlich gegen das Corpus geniculatum internum und externum hinziehen seben, während noch andere, die offenbar nach innen verliefen, wegen der zahlreichen Durchflechtungen mit normalen Faserzügen nicht weiter verfolgt werden konnten. Der Linsenkern schien dabei auch in seinem hintersten Abschnitte intact zu sein, während nach aussen von ibm Vormauer und Inselwindungen vollständig zerstört waren.

Fig. 7.

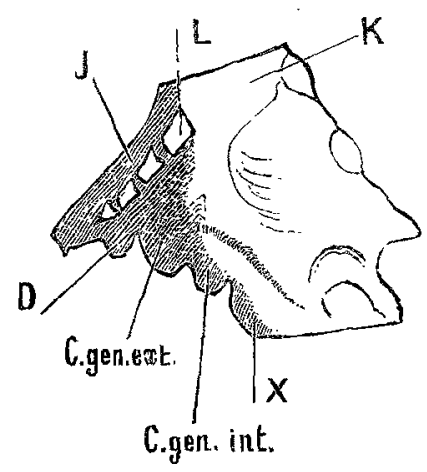

Fronta?schnitt durch das hinterste Ende des Linsenkerns. J. Erweichte Inselgegend. K. Innere Kapsel. D. Secundäre Degeneration. C. gen, ext. Corpus geniculatum externum. C. gen. int. Corpus geniculatum internum. L. Linsenkern. $x$. Degenerirtes Bŭudel, das zum lateralen Abschnitt des Fusses wird.

Die Stabkranzfasern, die rom Schläfenlappen berauf kommen, sind zum weit ans grössten Theile degenerirt, doch finden sich an Weigertpräparaten auch noch einzelne von anscheinend normalem Ausseben.

Auf Frontalschnitten, die mebr nach vorne zu angelegt sind, wird das gemeinschaftlicbe Degenerationsfeld immer kleiner, während es im grossen Ganzen seine Form und seine Lage beibehält, und verschwindet schliesslich in einer Frontalebene kurz vor dem Auftreten des III. Linsenkerngliedes vollständig. Kurz vor seinem Verscbwinden zeigt es noch eine nabezu dreieckige Gestalt und liegt genau an der Stelle, wo bald darauf das III. Glied des Linsenkerns auftreten wird. Nach aussen hin setat sich dasselbe hier in einen bellen sebmalen Streifen fort, der in einem Bogen über den Tractus opticus binwegzieht und ehe die Inselgegend erreicht ist, sich alliälig verliert. Auch hier erscheint der Linsenkern vollständig erbalten und sind insbesondere auch die sich an der Basis desselben als Linsenkernschlinge sammelnden Faserzüge ganz intact. Die oben erwäbnte Degeneration in der inneren Capsel. die auf Frontalschnitten durch den hintersten Alschnitt des Linsenkerns deutlich zo seben war und hier offenbar den degenerirten Faserzügen im lateralen $A b-$ schnitte des Fusses entsprach, liess sich nun noch auf einer ganzen Reihe von woiter nach vorne angelegten Frontalschnitten constatiren und verschwand erst 
vollständig bei Frontalebenen entsprechend der Mitte des II. Linsenkerngliedes. Von bier ab liessen die woiter nach rorne gelegten Frontalschnitte keine Spur einer Degeneration in der inneren Capsel mehr erkennen bis zu der Gegend dicht vor dem Corpus mamillare. Hier trat eine nene Degeneration auf, anfänglich in Form eines schmalen Streifens, der sich auf Schnitten weiter nach vorne verbreiterte und hier schliesslich mit einem kleinen Erweichungsherde in Zusammenhang stand, der in der Höhe des oberen Endes des II. Linsenkernes und in dessen Nähe innerhalb der Capsel gelegen war. Der obere Theil der inneren Capsel erwies sich anf allen diesen Frontalschnitten absolut frei ron Degeneration, ebenso anch auf allen weiteren Schnitten, die weiter nach vorne zu angelegt wurden.

Querschnitte durch den linken Pedunculus dicht über dem Pons ergeben ziemlich ausgedehnte, aber unregelmässig verbreitete Degenerationen im Fusse. Das änssere Viertel desselben ist total degenerirt, doch hebi sich an der ventralen Seite eine Zone als besonders stark degenerirt durch ihre hellere Färbung deutlich ab (Fig. 4a.) Hier sind alle Nervenfasern zerstört, wäbrend in deu lateralsten Partien noch anscheinend intacte Fasern vorbanden sind. Das daran stossende zweite Viertel des Fusses zeigt hauptsächlich in seinem nach der Mitte za gelegenen Theile ziemlich viele degenerirte Fasern, wähin dem äusseren Abschnitte die Nervenfasern zumeist gat erhalten sind. Das 3. Viertel zeigt eine sebr deutliche und ziemlich gleichmässige Abnahme der Nervenfasern, doch finden sich auch hier noch stellenweise ziemlich zahlreiche normal aussehende Fasern. Das innorste Viertel endlich ist in diffuser Weise ziemlich stark degenerirt, lässt aber auch noch normal aussebende Fasern erkennen. Nach abwärts kann man die Degeneration des lateralen und medialen Abschnittes wieder nur bis zur oberen Ponsetage verfolgen. Die linke Hälfte des Pons ist hier überall schmäler als die rechte und fällt in den rentral gelegenen Ponskernen vielfach anf, dass die Zellen etwas kieiner und derber erscheinen als in den entsprechenden Kernen der rechten Hälfte sowio dass das umspinnende Nervennetz spärlicher und feiner ist. Die Faserbündel der Pyramidenbahn sind in Pons und Medulla linkerseits entschieden kleiner als rechts und lassen auoh wakroskopisch deullich Zeichen einer Degeneration erkennen, doch ist letztere nichtsehr erheblich. Im Halsmarke ist dieselbe noch deutlich im Bereiche des rechten Seitenstranges za sehn, nimmt aber nach abwärts immer mehr ab, so dass im Lendenmark kaum noch ein Unterschied zwischen rechter und linker Pyramidenbahn zu erkennen ist.

Die Substantia nigra zeigt links keinen deutlichen Unterschied in Bezug auf Grösse und Ausdehnung gegenüber rechts, doch scheint es als wenn stellenweise die Zellen links etwas kleiner und seltener wären als rechts.

Das linke Corpus geniculatum internum ist erheblich kleiner als das rechte und total degenerirt in einer Weise analog den vorigen Fällen. Dagegen ist die Nervenfaserschicht, welche dasselbe umscheidet, sehr gut erhalten geblieben. Desgleichen zeigt

Das linke Corpus geniculatam externum zeigt eine deutliche Ver- 
kleinerung gegenüber dem rechten. Wie wir oben sahen, sind auch hierwie beim Corp. genicul. intern. die rom Stabkranz einstrablenden Fasern degenerirt und findet sich im Anschluss daran eine Atrophie zahlreicher Ganglienzellen; Körnchenzellen fehlen vollständig.

Das linke Pulvinar ist erbeblich in seinem Umfange reducirt und lässt oine Degeneration der aus dem sagittalen Marke in dasselbe einstrahlenden Faserzüge sehr deutlich erkernen, während die zonale Fasersebicht erhâten geblieken ist.

Der linke obere Vierbägel zeigt in seiner Deckschicht weniger Nervenfasern als der rechte, ausserdem sind dieselben durchweg sebr fein. Das linke Ganglion ist deutlich kleiner als das rechte. Auch im

unteren linken Vierbügel scheint das Ganglion kleiner zu sein als das rechte, trotzdem sich eine deutliche Degeneration im unteren Vierhügel nicht mit Sicherheit nachweisen liess.

Der linke Tractus resp. Nervus opticus liess keine degenerativen Veränderungen erkennen.

Im linken Thalamus opticus fand sich ausserdem noch in seiner vorderen Hälfte, und $z$ war in der Nähe der inneren Capsel ein schmaler, kleiner alter Erweichungsherd von der Form und Grösse eines kleinen Haferkornes.

Der rechte Pedunculus resp. Fuss erwies sich frei von Veränderungen; desgleichen liess auch die Schleife links keine Untersehiede gegenüber der rechten erkennen.

In beiden Fällen hatten wir es, wie wir sahen, mit grossen Erweichungsherden zu thun, die nahezu den gleichen Sitz und Ausdehnung in der linken Hemisphäre hatten. Dementsprechend fanden wir auch in beiden Fällen in tiefer gelegenen Hirnabschnitten fast die gleichen secundären Veränderungen. Unterziehen wir von diesen zuerst diejenigen des Pes pedunculi einer näheren Besprechung, so war derselbe in beiden Fällen fast vollständig, wenn auch in sebr ungleicher Weise degenerirt. Vorab erwies sich der laterale Abschnitt mehr oder weniger total verändert und $z$ war erinnerte das Bild der Degeneration hinsichtlich der Stärke und des Sitzes der Veränderung. im vierten Falle Philipps sehr an dasjenige, was der zweite Fall Flesch darbot, da in beiden Fällen sich eine Zone an der ventralen Fläche durch den totalen Schwund der Nervenfasern auszeichnete. Wie in den beiden ersten Fällen werden wir auch in diesen zwei Fällen die Degeneration des lateralen Viertels auf die Zerstörung der entsprechenden Hinterhaupts- und Schläfenlappen resp. auf Unterbrechung ihrer Marksubstanzen zurückführen dürfen, die ja thatsächlich in beiden Fällen zerstört waren. Die partielle Degeneration des zweiten, der Pyramidenbahn zukommenden Viertels ist auf die in 
beiden Fällen vorliegende Erweichung der unteren Abschnitte beider Centralwindungen resp. des zugehörigen Varklagers zurückzufübren. Diese Degeneration liess sich im Falle Foltz auf den Horizontalschnitten innerhalb der inneren Capsel nach oben weiter verfolgen und nahm ungefähr in der halben Höhe des Thalamus den hintersten Abschnitt der inneren Capsel ein. Hinsichtlich des dritten Viertels zeigten beide Fälle eine Differenz, indem dasselbe im Falle Foltz eine sehr geringe, im Falle Philipps dagegen stärkere degenerative Veränderungen aufwies. Es hing dies offenbar mit dem kleinen Erweichungsherde zusammen, der sich bei Philipps innerhalb der inneren Capsel vorfand und von dem aus sich, wie wir sahen, eine deutliche secundäre Degeneration nach abwärts verfolgen liess. Dieser Erweichungsherd lag ungefäbr in derselben Frontalebene, wie derjenige, den der Fall Flesch in der rechten Hemisphäre aufwies und der gleichfalls eine secundäre Degeneration im Bereiche des 3. Ventrikels im Pes pedunculi hervorgerufen hatte. Das mediale Viertel des linken Fusses zeigte dagegen wieder in beiden Fällen eine Degeneration von nahezu gleicher Stärke und Ausdebnung. Dieselbe war vielleicht im Falle Foltz etwas stärker und ausgedehnter als im Falle Philipps, doch sind gerade hier genaue Beurtheilungen wegen der vielen Umlagerungen und Durchflechtungen mit anderen dasselbe durchsetzenden Faserbündeln sehr schwierig.

Mit welchen Regionen und Theilen des Gehirns diese Degeneration des medialen Abschnittes in beiden Fällen zusammenhing, liess sich mit Sicherheit nicht feststellen. Man konnte jedoch einmal nachweisen, dass dieselbe nicht mit den Erweichungen der weissen Substanz im Bereich des Vorderhirns zusammenhing, da, wie dies der Fall Foltz mit Sicherheit ergab, die innere Capsel in den vordersten Abschnitten ibres hinteren Schenkels absolut frei von degenerativen Veränderungen war. Wir sahen nämlich oben, dass das Degenerationsfeld in der inneren Capsel auf schrägen Horizontalschnitten immer kleiner wurde, je weiter man nach oben kam und dass in einer Höhe, welche etwa der Hälfte des Thalamus entsprach, nur noch die hintersten Abschnitte der inneren Capsel degenerirt waren, somit der Abschnitt, den Flechsig für die vom Stirnhirn herkommenden Faserzüge in Anspruch nimmt, vollkommen intact war. Andererseits ljessen aber die Bilder, welche speciell der Fall Philipps lieferte, mit grosser Wahrscheinlichkeit die Annahme za, dass die degenerirten Partien im medialen Abschnitte als Fortsetzung von Fasern anzuseben sind, welche an der Basis des Linsenkerns in seinem hinteren Abschnitte von aussen her nach iunen verlaufen. Wir sahen nämlich 
oben auf Frontalschnitten im Falle Philipps, dass von der zerstörten Inselgegend her beständig degenerirte Faserzüge nach innen zu dem gemeinschaftlichen Degenerationsfelde hin liefen und konnten schliesslich auf Frontalebenen, welche den vordersten, bald darauf verschwin denden Abschnitt dieses Degenerationsbezirkes enthielten, noch erkennen, dass derselbe sich nach aussen hin in einen schmalen Streifen fortsetzte, der offenbar degenerirte Fasern enthielt und sich an der Basis des Linsenkerns allmälig verlor. Da dieses Degenerationsfeld aber auf Frontalschnitten fast gleichzeitig mit dem vordersten Abschnitte der zum Pes umgewandelten inneren Capsel verschwindet, so liegt die Vermuthung sehr nahe, dass dasselbe in dem vorderen resp. medialen $\mathbf{A b}$ schnitte des Fusses seine Fortsetzung findet. Wir werden demnach, da wir die von anssen unter der Basis des Linsenkerns herkommenden, degenerirten Faserbündel, als von der Inselgegend herstammend betrachten dürfen, zu der Annahme gelangen, dass die Degeneration im medialen Abschnitte des Fusses zum Theil wenigstens auf die Zerstörung der Inselgegend zurückzuführen sei. Ob hierbei ausserdem noch Fasern aus dem Linsenkern in Betracht kommen, geht aus dem Falle Philipps nicht herror, ist jedoch im Hinblick auf den Fall Foltz, bei dem, wie wir sahen, die basalen Theile des Linsenkerns in seinem hintersten Abschnltte erweicht waren, sehr leicht möglich. Die Degeneration in der medialen Hälfte liess sich analog der des lateralen Viertels nur bis zur oberen Ponsetage verfolgen, wo sie in den hier befindlichen Ponskernen ihr Ende fand. Deutliche Verschmälerungen dieser Kerne auf der linken Seite liessen sich bei Vergleichen mit der rechten Ponshälfte nicht erkennen, trotzdem die linke Hälfte dentlich schmäler war als die rechte, doch fielen atrophische Veränderungen an den Zellen sowie Abnabme der dieselben umspinnenden Nervenfasern in verschiedenen Kernen bei der mikroskopischen Untersuchung auf. Die Degeneration im Bereiche der Pyramidenbahn liess sich jedoch in beiden Fällen bis in das Rückenmark verfolgen, nahm jedoch hier nach abwärts immer mebr ab, so dass sie im Lendenmarke kaum noch nachweisbar war. Dabei war dieselbe im Falle Foltz entschieden stärker und ausgedehnter als im Falle Philipps. Es kann wohl kaum einem Zweifel unterliegen, dass dieselbe in beiden Fällen mit der Erweichung im Bereiche der Centralwindungen resp. ihrer Markstrahlungen zusammenhing, und ist es bemerkenswerth, dass entsprechend der Unversehrtheit der oberen Hälften der Centralwindungen die Degeneration sich in der unteren Hälfte des Rückenmarks sehr bald fast vollständig verlor.

bie Verschmälerung und Atrophie der linksseitigen Substantia 
nigra im Falle Foltz dürfte aller Wahrscheinlichkeit nach mit der Erweichung der basalen Partien des Linsenkerns zusammenbängen, welche die austretenden und zum Linsenkerne hinziehenden Faserzüge mit zerstört hatte. Dementsprechend fehIt anch im Falle Pbilipps diese Verschmälerung der linken Substantia nigra.

In beiden Fällen fand sich ferner analog dem Falle Bey eine secundäre Degeneration des Corpus geniculatum externum, die wir gleich den Veränderungen im vorderen Vierbügel und Pulvinar auf die Zerstörung resp. Unterbrechung der im sagittalen Marke verlaufenden Faserbündel zurückführen müssen. Diese Degeneration des Corpus genicul. externum war im Falle Foltz eine besonders ausgesprochene und ausgedehnte, weil sie offenbar von zwei Seiten her bedingt war, nämlich einerseits durch Unterbrechung des sagittalen Markes, andererseits in Folge der linksseitigen Opticusatrophie, die ihrerseits mit der Atrophie des Bulbus zusammenhing und anscheinend sehr alten Datums war. Letztere hatte offenbar auch die degenerativen Veränderungen im rechten Tractus opticus hervorgerufen. Schliesslich boten beide Fälle auch eine sehr ausgesprochene Degeneration des linken Corp. geniculatum internum dar, wie sicb dies nach den Ergebnissen der zwei ersten Beobachtungen auch erwarten liess. Wäbrend sich aber im Falle Foltz deutliche degenerative Veränderungen im Bereiche des linken unteren Vierhügelarmes bei anscheinend intactem Verhalten des aus dem Corp. geniculatum intern. herstammenden Faserbündels nachweisen liessen analog den ersten Beobachtungen, war dies im Falle Philipps mit genügender Sicherheit nicht möglich. Immerhin fand sich jedoch auch hier, rass das Ganglion des linken unteren Vierhügels etwas kleiner war als das rechte.

Der Fall Foltz war ausserdem, wie wir sahen, noch dadurch ausgezeichnet, dass der linke rothe Kern deutlich kleiner war als der rechte, und dass sich im Thalamus opticus stellenweise reichliche Körnchenzellen vorfanden. Aller Wahrscheinlichkeit hingen diese secundären Veränderungen mit der Erweichung resp. Unterbrechung von Faserzïgen ans dem Linsenkern zusammen, doch liess sich dies in diesem Falle bei der Ausdebnung der Erweichung und Vielfältigkeit der secundären Degenerationen nicht mit Sicherheit feststellen. Ein Gleiches gilt auch von dem kleinen Degenerationsbezirke, der sich neben dem medialen Ende des Pes pedunculi vorfand und den ich unter aller Reserve für einen degenerirten Theil der Linsenkernschlinge ansprechen möchte. 
In klinischer Hinsicht ist über die beiden Fälle nicht viel zu sagen, da der psychische Zustand derselben eine genauere klinische Untersuchung ausschloss. Das eigenartige Krankheitsbild, welches Philipps darbot, vor Allem die hochgradige Apathie und Willenlosigkeit ist wohl dadurch zu erklären, dass sich bei demselben neben dem Erweichungsherde auch noch diffuse Erkrankungen in dem Gehirne vorfanden, die durch die geringe Atrophie der Windungen, die auffällige Weite der Seiten und die Granulirung des IV. Ventrikels sowie durch weit verbreitete Piaveränderungen genugsam erklärt sein dürften. Auffallend erscheint in dem klinischen Bilde nur, dass Patient, trotzdem sich eine Erweichung der unteren Partien der linken Centralwindungen und davon abbängig eine partielle secundäre Degeneration der Pyramidenbahn vorfand, zu Lebzeiten keine Spur einer motorischen Lähmung anfgewiesen hatte. Es ist dies um so auffallender im Hinblick auf den Fall Foltz, der bei annähernd gleichem Sitz und Ausdehnung der Erweichung im Bereiche der Centralwindungen eine ausgesprochene Lähmung und Contractur im rechten Arme und eine Parese im rechten Beine darbot. Allerdings war die secundäre Degeneration im Rückenmarke im letzteren Falle eine ausgesprochenere und intensivere, immerhin war sie jedoch auch im Falle Philipps deutlich ausgeprägt und speciell im Bereiche des Hals- und oberen Brustmarkes nicht zu verkennen.

Die im Falle Foltz sebr deutlich ausgesprochene halbseitige Anästhesie und Analgesie dürfte wohl höchst wahrscheinlich auf die Zertörung des unteren Scheitellappens zurückzuführen sein; wenigstens zeichnete sich dieser Fall vor allen übrigen, bei denen keine derartige Gefühlslähmung vorlag, gerade dadurch aus, dass bei ihm der ganze untere Scheitellappen im Bereiche der Erweichung lag. Ob diese Zerstörung des Scheitellappens irgend welche secundäre Degeneration hervorgerufen hatte, liess sich nicht feststellen, da bei der ausgebreiteten Erweichung die einzelnen degenerirten Faserzüge im Stabkranz nicht isolirt nach abwarts verfolgt werden konnten. Andererseits läge die Annahme nahe, dass vom Scheitellappen aus, falls sich dort wirklich das centrale Ende der sensiblen Nervenfasern befände, überhaupt keine Degeneration vach abwärts einträte.

Fassen wir nun zum Schlusse die wesentlichsten Ergebnisse der Untersuchung unserer vier Fälle zusammen, so beziehen sich dieselben vor Allem auf die Kenntniss des Faserverlaufes im Grosshirnschenkelfusse. Aif Grund dieser Untersuchungen und unter Berücksichtigung der bisher über diesen Gegenstand bekannt gewordener Beobachtungen und Untersuchungen darf nunmehr Folgendes über di 
verschiedenartigen im Pes pedunculi verlaufenden Fasersysteme als mebr oder weniger feststehend betrachtet werden.

Theilt man den Fuss") auf einem Querschnitte des Grosshirnschenkels dicht über dem Pons in vier annähernd gleiche Theile ein, so finden sich im äussersten Abschnitte Fasern, die vom Hinterhauptslappen sowie rom Schläfenlappen herkommen und durch diesen Theil des Fusses bis zur oberen Etage des Pons hinabsteigen, wo sie ihr vorläufiges Ende finden. $O b$ diese Faserzüge derart gelagert sind, dass die vom Hinterhauptslappen herkommenden die äussere Peripherie einnehmen, kann als wahrscheinlich, wenn auch noch nicht als erwiesen angeseben werden; ebenso muss es einstweilen noch dahingestellt bleiben, ob auch Fasern vom Scheitelhirn im lateralen Abschnitte des Fusses vertreten sind, da dies bis jetzt trotz der Fälle von Sioli und Winkler noch nicht als endgültig bewiesen gelten kann. Das zweite äussere Viertel des Fusses wird ausschliesslich von der Pyramidenbahn eingenommen. Dieser Satz kann nunmehr als absolut feststehend betrachtet werden in Uebereinstimmung mit der Lehre Flechsig's nud im Gegensatze zu der von klinischer Seite bisher festgehaltenen Anschaunng. In allen Fällen von Erweichung innerhalb der inneren Capsel, bei denen sich secundär ein grösserer Abschnitt des Fusses in dieser Gegend als das zweite Viertel beträgt, degenerirt fand, müssen demnach noch andere Faserbündel als die Pyramidenbahn mit zerstört gewesen sein. Zumeist handelte es sich offenbar um Faserzüge, die nach innen von der Pyramidenbahn im Fusse nach abwärts ziehen, Fasern, die uach meinen Untersuchungen mit der eigentlichen Pyramidenbahn nichts zu thun haben, und die bereits im oberen Theil des Pons ihr Ende fiuden. Diese Faserzüge, welche ich das dritte Viertel von aussen gerechnet einnehmen lasse, stammen höchst wahrscheinlich zum grössten Theile aus dem Corpus striatum, möglicherweise zum Theil auch aus den hintersten Abschnitten der Stirnwindungen resp. der vorderen Centralwindung. Jedenfalls sind es dieselben Faserzüge, die in einer Frontalebene dicht hinter dem Capselknie die innere Capsel in ihrem oberen Abschnitte, etwa im obersten Drittel passiren und im weiteren Abstieg dicht vor der Pyramidenbahn liegen. Es stimmen somit die Ergebnisse unserer Untersuchungen auch

*) Diese Eintheilung ist eine willkürliche und geschieht nur der Vebersicht halber. In Folge dessen sind auch die folgenden Angaben über Lage und Ausdehnung der einzelnen Faserbündel nur als relatir gültige anzusehen. 
hinsichtlich dieser Faserzüge zum grossen Theil wenigstens mit den von Flechsig gefundenen Resultaten überein. Bekanntlich lässt dieser Forscher in der medialen Hälfte des Fusses Fasern vom Corpus striatum, vom Stirnhirn und von vorderen Abschnitten des Linsenkerns nach abwärts steigen, räumt aber, wie dies aus seiner Fig. 3 hauptsächlich hervorgeht, den aus dem Corpus striatum kommenden Fasern im Abstieg durch die innere Capsel den Platz dicht vor der Pyramidenbahn ein. Es liegen aber gerade diese Faserzüge, wie unsere Untersuchungen ergeben, im dritten Viertel des Fusses nach innen zu an die Pyramidenbahn anstossend.

Dagegen gehen die Ergebnisse unserer Untersuchungen hinsichtlich der im innersten Abschnitte des Fusses gelegenen Faserzüge mit denen von Flechsig vollständig auseinander. Während, wie wir soeben hörten, hier Flechsig Fasern aus dem Stirnhirn resp. Linsenkern annimmt, ging aus unseren Untersuchungen mit aller Bestimmtheit hervor, dass Fasern vom Stirnhirn hier nicht verlanfen. Hatten dies bereits die früher untersuchten Fälle Schreyer und Schweblin (l. c.) mit grosser Sicherheit durch ihre negativen Resultate ergeben, so beweisen es die beutigen Fälle Foltz und Philipps durch ihre positiven Ergebnisse, ganz in Uebereinstimmung mit dem schon oben angeführten Falle von Brink, bei dem sich auch trotz Zerstörung der Markstrahlungen des Stirnhirns keine Degeneration im medialen Abschnitte des Pes vorfand. Im Gegensatze zu Flechsig gelangten wir nun zur Annabme, dass im innersten Abschnitte des Fusses höchst wahrscheinlich Faserzüge, die von der Inselgegend resp. von der Basis des Linsenkerns herstammen, verlaufen, um in der oberen Ponsetage gleichfalls vorläufig zu endigen. Diese Ansicht, welche ich vorerst noch mit einer gewissen Reserve anfstellen möcbte, würde in gewissem Sinne als eine Ergänzung der Wernicke'schen Anschauung gelten können, der zu Folge Faserzüge aus dem Stirnhirn auf dem Umwege durch den Linsenkern zum inneren Abschnitte des Fusses gelangen.

Weitere wichtige Ergebnisse lieferten unsere Fälle im Hinblick auf das Corpus geniculatum internum. Ueber dasselbe herrscht bekanntlich bis heute noch ein gewisses gebeimnissvolles Dunkel sowohl was seine anatomischen Beziehungen zu anderen Gehirnabscbnitten, als auch was seine physiologische Bedeutung anbelangt. Unsere Beobachtungen dürften nun nach beiden Richtungen hin einiges Licht verbreiten. Wie wir oben sahen, fand sich dasselbe in allen vier Fällen secundär degenerirt und gelangten wir im Anschluss an den Fall Flesch zur Ansicht, dass diese Degeneration höchst wahrscheinlich 
von der Zerstörung des linken Schläfenlappens respective der zwei oberen Schläfenwindungen abhängig sei, eine Annahme, mit der auch die drei übrigen Fälle übereinstimmen würden. Sollte sich diese Annahme als richtig erweisen, so läge hier ein ganz analoges Verhältniss vor, wie wir es zwischen dem Corpus geniculatum extern. und gewissen Abschnitten des Hinterbauptslappens bereits kennen. Diese Analogie erscheint aber noch viel weitgehender, wenn wir in Betracht ziehen, dass sich neben der Degeneration im Corpns geniculatum internum auch noch degenerative Veränderungen im unteren Vierhügelarm sowie im unteren Vierhügel vorfanden, die aller Wahrscheinlichkeit gleichfalls von der Zerstörung des Sehläfenlappens abbängen. Wir hätten somit zwei parallele Fasersysteme, einmal dasjenige, welches die directen Faserzüge vom Hinterhauptslappen zum Corpus geniculatum externum sowie zum oberen Vierhügel enthält, und welches offenbar in der Rinde des Hinterhauptslappens sein trophisches Centrum hat und andererseits dasjenige, welches directe Faserzüge vom Schläfenlappen zum Corpus geniculatum internum und zum unteren Vierbügel umfasst und das nach Zerstörung des Schläfenlappens degenerirt. Nun haben aber die Untersuchungen Flechsig's*) und anderer Forscher ergeben, dass der untere Vierhügel durch Vermittelung der lateralen Schleife mit dem Nervus acusticus zusammenhängt und als ein Centralorgan des Hörnerven anzusehen ist; wir hätten demnach ein in sich vollständig abgeschlossenes System von Nervenfasern, welches unter Vermittelung von "Umschaltungsplätzen“ eine directe Verbindung von der Peripherie, vom Nervus acusticus bis zum corticalen Centralorgan, der Rinde des Schläfenlappens herstellt. Es wird somit die Analogie mit dem vorhin sehon zum Vergleiche herangezogeneu Sehfasersysteme eine vollständige. Andererseits wird aber durch diese Herstellung der anatomischen Verbindung auch das physiologische Verständniss für das Corpus geniculatum internum erschlossen. Denn da es heute keinem $\mathrm{Z}_{w}$ eifel mehr unterliegen kann, dass der linke Schläfenlappen resp. seine $z$ wei oberen Windungen zu der Fähigkeit Gehörtes zu verstehen in innigster Beziehung steht, so werden wir mit Recht annehmen dürfen, dass das Corpus geniculatum zum Gehörsinn in sehr naher Beziehung steht, gerade so wie wir dies für das Corpus genicul. extrernum in Bezug auf den Gesichtssinn annehmen. Näher auf diesen Gegenstand hier einzugeben, liegt ausser dem Rahmen der vorliegenden Arbeit, er-

*) Neurolog. Centralbl. 1886 und 1890. 
698 Dr. Theodor Zacher, Beiträge zur Kenntniss des Faserverlaufes etc.

scheint auch müssig insofern als die hierauf bezüglichen anatomischen Ergebnisse unserer Arbeit nicht als absolut sichere gelten dürfen.

Ebenso kann ich es unterlassen, noch besonders auf andere Resultate unserer Arbeit, speciell auf die durch dieselbe von Neuem constatirten engen Beziehungen des Hinterhauptslappen zu den niederen Opticuscentren hinzuweisen, da ich damit doch nichts Neues bringen würde.

Ich schliesse somit, indem ich meinem Chef auch an dieser Stelle für die freundliche Ueberlassung des Materials meinen Dank ausspreche. 